\title{
Dynamics, stratospheric ozone, and climate change
}

Article

Accepted Version

Shepherd, T. G. (2008) Dynamics, stratospheric ozone, and climate change. Atmosphere-Ocean, 46 (1). pp. 117-138. ISSN 1480-9214 doi: https://doi.org/10.3137/ao.460106 Available at https://centaur.reading.ac.uk/31773/

It is advisable to refer to the publisher's version if you intend to cite from the work. See Guidance on citing.

To link to this article DOI: http://dx.doi.org/10.3137/ao.460106

Publisher: Taylor \& Francis

All outputs in CentAUR are protected by Intellectual Property Rights law, including copyright law. Copyright and IPR is retained by the creators or other copyright holders. Terms and conditions for use of this material are defined in the End User Agreement.

\section{www.reading.ac.uk/centaur}

\section{CentAUR}

Central Archive at the University of Reading

Reading's research outputs online 
Submitted to Special Issue of Atmos.-Ocean (20 ${ }^{\text {th }}$ Anniversary of Montreal Protocol)

\title{
Dynamics, Stratospheric Ozone, and Climate Change
}

\author{
Theodore G. Shepherd \\ Department of Physics, University of Toronto \\ 60 St. George St., Toronto, Ontario M5S 1A7 Canada
}

Submitted May 15, 2007

Revised August 31, 2007

tel. (416) 978-2931; fax (416) 978-8905

email: tgs@atmosp.physics.utoronto.ca 


\begin{abstract}
Dynamics affects the distribution and abundance of stratospheric ozone directly through transport of ozone itself, and indirectly through its effect on ozone chemistry via temperature and transport of other chemical species. Dynamical processes must be considered in order to understand past ozone changes, especially in the Northern Hemisphere where there appears to be significant low-frequency variability which can look "trend-like" on decadal timescales. A major challenge is to quantify the predictable, or deterministic, component of past ozone changes. Over the coming century, changes in climate will affect the expected recovery of ozone. For policy reasons it is important to be able to separately attribute the effects of ozone-depleting substances and greenhouse gases on both ozone and climate. While the radiative-chemical effects can be relatively easily identified, this is not so evident for dynamics — yet dynamical changes (e.g. changes in the Brewer-Dobson circulation) could have a first-order effect on ozone over particular regions. Understanding the predictability and robustness of such dynamical changes represents another major challenge. Chemistry-climate models have recently emerged as useful tools for addressing these questions, as they provide a self-consistent representation of dynamical aspects of climate and their coupling to ozone chemistry. We can expect such models to play an increasingly central role in the study of ozone and climate in future years, analogous to the central role of global climate models in the study of tropospheric climate change.
\end{abstract}




\section{Introduction}

Whilst stratospheric ozone depletion is a chemical phenomenon, caused by the emission of anthropogenic halogenated compounds into the atmosphere, chemical ozone loss is controlled by atmospheric dynamics. Dynamics explains why it is that ozone loss is much more severe in the Antarctic springtime than it is in the Arctic springtime. Dynamics also explains why ozone loss exhibits year-to-year variability even while the halogen loading evolves more smoothly, and why this variability is largest in the Northern Hemisphere. Moreover, dynamical variability also leads to changes in ozone abundance through changes in transport. Observed changes in ozone thus result from both dynamical and chemical effects, and in a non-additive manner. It follows that in order to detect and attribute the chemical ozone loss resulting from anthropogenic halogens, it is necessary to understand and account for the role of dynamics.

At the time of the last Environment Canada report on ozone, on the $10^{\text {th }}$ anniversary of the Montreal Protocol, the halogen loading of the stratosphere was still increasing and the main issues concerning the role of dynamics in ozone changes were those mentioned above. Today, ten years on and with the stratospheric halogen loading slowly declining, the questions have evolved considerably. Now, the issue of detection and attribution has changed from that of ozone depletion to that of the onset of ozone recovery. Looking further ahead, with the overall halogen abundance projected to return to pre-1980 levels around the middle of the century (or even later in polar regions), the question arises as to how climate change will affect the future state of the ozone layer, and how the full recovery of stratospheric ozone from the effects of ozone-depleting 
substances (i.e. in the sense of the Montreal Protocol) can be detected and attributed against the backdrop of a changing stratosphere.

The purpose of this article is to review the role of dynamics in determining stratospheric ozone abundance and ozone depletion, and our current understanding of how climate change might affect this. Section 2 reviews the basic dynamical processes relevant to ozone abundance and ozone depletion, building on the discussion in Fioletov (2007). Section 3 applies these concepts to understanding the observed record of ozone changes. Section 4 discusses the possible dynamical impact of climate change on the future state of the ozone layer, complementing the discussion of the direct radiativechemical effects in McConnell (2007). The effect of ozone depletion on climate is treated in McFarlane (2007). Section 5 summarizes the latest assessment of the past and future state of the ozone layer using fully interactive chemistry-climate models (CCMs), using results from the Canadian Middle Atmosphere Model (CMAM) to illustrate the major findings. The paper concludes with a summary of the overall current understanding and discusses the open questions and future research directions in this area.

For readers requiring more background than can be provided here, a physicallybased introduction to large-scale atmospheric dynamics (including a glossary of technical terms), with extensive treatment of the stratosphere, can be found in Shepherd (2003). More advanced reviews of key concepts and recent developments in stratospheric dynamics can be found in Shepherd (2000) and Haynes (2005), while stratospheric transport is reviewed in Plumb (2002) and Shepherd (2007). In addition to providing more detail on many of the points covered here, these reviews provide extensive references to the scientific literature. 


\section{The role of dynamics in ozone abundance and ozone depletion}

In the upper stratosphere (outside of polar night), the chemical lifetime of ozone ${ }^{\dagger}$ is much shorter than transport timescales, the latter being on the order of weeks. It follows that ozone is under photochemical control and transport of ozone has little impact on ozone abundance (see McConnell 2007). The primary effect of dynamics on ozone is via temperature and the transport of long-lived species (e.g. $\mathrm{H}_{2} \mathrm{O}, \mathrm{NO}_{\mathrm{y}}, \mathrm{Cl}_{\mathrm{y}}$ ) that provide catalysts for ozone chemistry, and the ozone distribution is approximately the same in the two hemispheres (Figure 1 of Fioletov 2007). Below about $30 \mathrm{~km}$ (and in polar night), the lifetime of ozone is comparable to or longer than transport timescales and ozone is strongly affected by transport. Because most ozone is found in the lower stratosphere, the column ozone distribution largely reflects the distribution in the lower stratosphere and exhibits a significant asymmetry between the hemispheres, maximizing in the winterspring seasons (Figure 2 of Fioletov 2007). This asymmetry arises because of dynamics, and is well understood.

Between early fall and late spring, when stratospheric winds are westerly (reflecting, through thermal-wind balance, the low temperatures found in polar regions due to the lack of solar heating), planetary-scale Rossby waves generated in the troposphere by topography and land-ocean thermal contrasts can propagate up into the stratosphere where they grow in amplitude, break, and dissipate. In this process the waves

\footnotetext{
$\dagger$ Strictly speaking, when we speak of the chemical lifetime (or, for that matter, transport) of ozone in the stratospheric context, we really mean the chemical lifetime (or transport) of odd oxygen, as ozone rapidly recycles within the odd oxygen family but this involves no net loss or gain of ozone (McConnell 2007). However we retain the more common (if strictly incorrect) usage in this article.
} 
transfer negative angular momentum from troposphere to stratosphere and the resulting negative torque, known as wave drag, drives a poleward circulation in the stratosphere. Mass continuity and the relaxational nature of infrared radiative cooling then leads to upwelling in the tropics and downwelling in the extratropics. The effect on ozone is to bring ozone down from its production region in the tropical upper stratosphere into the extratropical lower stratosphere, where its lifetime is long. Although transport in itself cannot change ozone abundance, the rapid chemical replenishment of ozone in the upper stratosphere together with the poleward transport implies a net increase in extratropical column ozone through the winter-spring season.

Because there is considerably more longitudinal asymmetry in the distribution of land and ocean in the Northern than in the Southern Hemisphere, the planetary-wave drag during winter and spring is much stronger in the Northern than in the Southern Hemisphere, leading to a larger springtime ozone maximum in the former. Between late spring and early fall, when the stratospheric winds are easterly (reflecting the high temperatures found in polar regions due to extensive solar heating, and the small amount of thermal inertia in the stratosphere compared with the troposphere), planetary-scale Rossby waves are prohibited from propagating into the stratosphere. As a result the circulation essentially shuts off and ozone declines towards photochemical equilibrium. By late summer the ozone abundances in the two hemispheres are quite similar (Figure 2 of Fioletov 2007).

This poleward circulation in the winter-spring hemisphere, known as the BrewerDobson circulation, also affects the zonal wind and temperature in the stratosphere. Downwelling leads to adiabatic warming which is ultimately balanced by increased 
radiative cooling from the higher temperatures, to allow a persistent circulation. More downwelling implies more warming. This explains why the Northern Hemisphere in winter and spring not only exhibits a higher ozone abundance in the extratropical lower stratosphere than does the Southern Hemisphere, but also higher temperatures. This interhemispheric temperature difference has important implications for ozone chemistry. It turns out that the wave drag in the Northern Hemisphere is just strong enough to generally keep Arctic temperatures above those required for extensive formation of polar stratospheric clouds (PSCs), while in the Antarctic the somewhat lower temperatures generally allow widespread occurrence of PSCs in the lower stratosphere (see McConnell 2007). The average difference in temperature is only about $10 \mathrm{~K}$, but it is a critical $10 \mathrm{~K}$ in terms of ozone depletion.

Chemical species are affected by a combination of the mean meridional mass circulation described above, and mixing. Because of the strong vertical stratification in the stratosphere, the mixing is mainly quasi-horizontal, along isentropic surfaces. In fact to a first approximation one can regard stratospheric transport as arising from the vertical motion connected with the Brewer-Dobson circulation, and quasi-horizontal mixing. The latter also arises from planetary-wave breaking and is thereby linked to the vertical motion, albeit in a non-local way. Because planetary-wave breaking is spatially inhomogeneous, so too is the quasi-horizontal mixing (Pendlebury and Shepherd 2003). In particular, the breaking generally occurs within the so-called "stratospheric surf zone" in a nonlinear critical layer (for stationary waves, close to the zero-wind line), and tends to be shielded from the pole by the polar vortex — the strong westerly flow that encircles the pole and is in thermal-wind balance with the low polar temperatures. 
Because Antarctic wintertime temperatures are lower than Arctic wintertime temperatures, the polar vortex is stronger and the shielding more effective in the Antarctic. Thus, the Antarctic vortex is quite well isolated from mixing with midlatitude air. This isolation is in fact an essential ingredient in the formation of the ozone hole (see McConnell 2007). Moreover, even before the development of the ozone hole, the latespring ozone maximum in the Southern Hemisphere occurred not over the pole (as in the Northern Hemisphere) but at subpolar latitudes, with ozone transport effectively "blocked" at the vortex edge and with a local minimum in column ozone occurring within the vortex (Figure 2 of Fioletov 2007). This local minimum has, of course, been deepened significantly by the chemistry of the ozone hole.

When the polar vortex breaks up in late spring, polar air is rapidly mixed with midlatitude air, spreading ozone-depleted polar air into midlatitudes. The period of mixing is short-lived, because once the stratospheric winds become easterly, planetarywave propagation is suppressed and the summertime stratosphere becomes quiescent. In some years "fossil" structures can be identified which survive the mixing associated with the vortex breakdown and which maintain anomalous tracer values well into summer (Orsolini 2001, Manney et al. 2006). However they are of limited spatial extent, and for the most part there is no longer any dynamical distinction between polar and midlatitude regions in summer. This is reflected in the long-term ozone trends, which differ between polar and middle latitudes through the winter and spring, but are identical through summer and into early fall (Figure 1).

The total extratropical trends shown in Figure 1 are just the area-weighted average of the polar and midlatitude trends. As shown by Fioletov and Shepherd (2005), the 
decline of the total extratropical trends between spring and early fall, in both hemispheres, is the result of the same photochemical relaxation that causes the decline in total extratropical ozone itself. However the large springtime polar trends in the Southern Hemisphere associated with the ozone hole evidently make a significant contribution to the midlatitude trends once the ozone-depleted polar air is mixed into midlatitudes following the breakdown of the vortex in early summer. This process accounts for the lack of a strong seasonal dependence to the Southern Hemisphere midlatitude trends (Fioletov and Shepherd 2005). In contrast, in the Northern Hemisphere the long-term springtime polar ozone trend is not much different from the midlatitude trend, so has little impact on the summertime midlatitude trend. As a result, the midlatitude trend exhibits a distinct seasonality which, like the total extratropical trend, reflects the seasonality of the ozone distribution itself (Fioletov and Shepherd 2003).

\section{Effect of dynamical variability on past ozone changes}

The stratosphere exhibits year-to-year variability, most notably in the wintertime when planetary-wave forcing is operative. There are various sources of interannual variability. Variations in solar radiation represent an external, natural forcing. The direct effects on ozone are discussed in Fioletov (2007) and McConnell (2007). Because ozone changes imply temperature and hence zonal-wind changes, there are also potential indirect effects arising from changes in wave drag, which would further affect ozone. The mechanisms for this remain somewhat speculative although they are the subject of current research (Gray et al. 2006). 
Another external, natural forcing is volcanic eruptions. As with solar variations these have a direct impact on ozone, in this case through the aerosol loading of the stratosphere. It is generally believed that the Mount Pinatubo volcanic eruption contributed to the low ozone abundances seen in the Northern Hemisphere extratropics in the early 1990s (Section 4.6.8 of WMO 2003). However there was no evidence of a volcanic signal in Southern Hemisphere ozone; and there have been a number of studies suggesting that the low ozone values seen in the Northern Hemisphere were associated with circulation changes (Hadjinicolaou et al. 1997), perhaps induced by the Mount Pinatubo eruption itself (Stenchikov et al. 2004). Volcanic eruptions could induce stratospheric circulation changes through warming of the tropical lower stratosphere (as the aerosol increases the absorption of upwelling infrared radiation), which would alter the distribution of zonal winds and hence of stratospheric wave drag. That these circulation changes would have been evident only in the Northern Hemisphere is explainable by the much stronger wave drag in the Northern Hemisphere (Section 4.6.8 of WMO 2003). Warming of the tropical tropopause provides another mechanism by which volcanic eruptions can affect stratospheric ozone: by allowing more water vapour into the stratosphere, the $\mathrm{HO}_{\mathrm{x}}$ budget can be perturbed for $\sim 5$ years or so (Figure 4 of Shepherd 2002).

A coherent internal source of natural variability is provided by the Quasi-Biennial Oscillation (QBO). The QBO is an oscillation in tropical zonal winds between easterly and westerly, which is not exactly periodic but has an average period of roughly 28 months. The QBO is forced by equatorial waves propagating up from the troposphere. Whilst in the extratropics the long-term response to wave forcing is a persistent 
meridional circulation, in the tropics the weakness of the Coriolis torque means that the wave forcing leads mainly to a zonal wind response, which propagates downward and can lead to oscillating states (Baldwin et al. 2001). The QBO affects ozone in tropical latitudes in various ways, all associated with the (weak) tropical circulation induced by the $\mathrm{QBO}$. But by changing the location of the zero-wind line, the $\mathrm{QBO}$ also affects the location of the stratospheric surf zone (Holton and Tan 1980). In particular, when the QBO is in its westerly phase, the surf zone extends into the tropics and the wave drag is further away from the pole, leading to less polar downwelling, a colder and stronger vortex, and lower polar ozone abundance (both dynamically and chemically).

But even apart from these coherent sources of interannual variability which have well-defined temporal signatures, there are incoherent variations in stratospheric wave drag with a broad frequency spectrum. At a fundamental level, these simply reflect the chaotic nature of atmospheric dynamics. Idealized studies have shown that even for fixed tropospheric forcing, the stratosphere can exhibit internal variability (Scott and Haynes 1998), and that there is a mechanism for interannual memory in the tropical zonal winds (Scott and Haynes 1998; Semeniuk and Shepherd 2001). But of course the tropospheric forcing is not fixed, because the troposphere itself exhibits interannual variability. Exactly what aspects of tropospheric variability are most important for generating stratospheric variability is not well understood — both sea-surface temperatures and the structure of the tropospheric wind field are likely contributors - but it is certainly clear that the troposphere represents a source of stratospheric variability on all timescales. This complicates the interpretation of long-term changes in ozone. 
Interannual variations in stratospheric planetary-wave drag are observed to affect ozone in the expected way: more wave drag implies a stronger Brewer-Dobson circulation and hence a stronger buildup of extratropical ozone in the winter-spring period (Fusco and Salby 1999; Randel et al. 2002). Figure 2 shows the observed seasonal cycle of extratropical ozone in the two hemispheres, with each curve representing an individual year. In order to focus on interannual variability, the long-term trend (represented by the fit to Equivalent Effective Stratospheric Chlorine, EESC) is removed from the time series and the anomalies are added to the fit at 2000. Although each year exhibits a winter-spring buildup, there is considerable interannual variability, in both hemispheres, in the strength of this buildup. Moreover the anomalies established through winter and spring persist through summer into early fall, until the next year's ozone buildup begins. The amplitudes of the summertime anomalies decay, in line with the overall photochemical relaxation, but remain coherent with high correlation coefficients (Fioletov and Shepherd 2003, 2005). Thus, dynamical variations in winter and spring account for the ozone variations found in summer. In fact, since ozone decays during summer, more ozone buildup in winter and spring implies more chemical ozone loss in summer (Weber et al. 2003): chemistry can only destroy what dynamics has provided in the first place.

Variations in stratospheric wave drag affect all latitudes. Because these variations affect the Brewer-Dobson circulation there is an approximate compensation between tropical and extratropical variations, in line with the compensation between tropical and extratropical temperature variations (Yulaeva et al. 1994): when extratropical ozone is high (anomalous downwelling bringing down more ozone from the upper stratosphere), 
tropical ozone is low (anomalous upwelling bringing up more ozone-poor air from below) (Fusco and Salby 1999). Within the extratropics, the midlatitude and polar variations are not particularly correlated during winter and spring (Fioletov and Shepherd 2005). Instead, there is latitudinal coherence within each region. However once the vortex breaks down, the variations are coherent within the entire extratropics. This latitudinal structure in the interannual variations is mirrored in the long-term trends (Figure 1).

Within polar regions, the interannual variations in wave drag strongly modulate temperature (Newman et al. 2001). In the Arctic, temperatures are close to the threshold for PSC formation and this temperature modulation is therefore reflected in significant variations in chemical ozone loss. A variety of independent methods have been used to quantify chemical ozone loss and find (under current conditions) roughly a linear dependence on temperature (Rex et al. 2004). Since weaker downwelling corresponds to both less ozone transport and more chemical ozone loss (because of lower temperatures), the two effects tend to act in the same sense and one may regard the chemical loss as amplifying the dynamical variations in ozone. Within the Arctic vortex, the interannual variations in chemical ozone loss explain about one-half of the observed variations in total ozone (Rex et al. 2004). It follows that the remaining one-half of the observed variations must be associated with changes in transport. Stated differently, within the Arctic vortex the chemical ozone loss (under current conditions) amplifies the year-toyear dynamical variations by roughly a factor of two.

The observed relationship between wave drag and ozone variability, during the past decade while stratospheric halogen loading was near its peak, is depicted for both 
polar regions in Figure 3. The ozone index used is the late-spring/early-autumn ratio of total ozone over $50^{\circ}-90^{\circ}$; as ozone decays photochemically during the summer, high values of this ratio correspond to years with a large winter-spring ozone buildup (and a small winter-spring chemical ozone loss), and are seen to be associated with strong wave drag. The relationship is remarkably linear and, perhaps even more remarkably, the same relationship encompasses both poles. Although the Antarctic values are mainly clustered together, the anomalous spring of 2002, which exhibited an unprecedented stratospheric sudden warming (see Shepherd et al. 2005), lies roughly mid-way between the typical Antarctic and Arctic values. Inserted within Figure 3 are images of the total ozone distributions over the poles in four of the winters, to illustrate the continuous transition from severe to essentially no polar ozone depletion. Yet even the most severe Arctic depletion is less severe than the least severe Antarctic depletion.

Figure 3 illustrates why linear regression analyses using wave forcing as an explanatory variable need to be used with care. From this linear relation, which has an exceptionally high correlation coefficient, one might naively conclude that the ozone variations were entirely attributable to meteorological variations; yet while the timing of the variations is certainly attributable to dynamics, their magnitude is partly attributable to chemical ozone loss. In polar regions, dynamical and chemical effects are strongly coupled.

Over the longer term, the observed time series of springtime polar ozone is quite different in the Arctic and Antarctic (Figure 4). In the Antarctic, the development of the ozone hole during the 1980 s as the halogen loading built up is evident, and the ozone hole was essentially saturated during the 1990s. There are some interannual variations 
(notably 2002) but in every year since the mid-1980s there is a marked depletion of ozone relative to the mid-1970s. In the Arctic, the interannual variability is very high (cf. Figure 3) and in some years there is virtually no ozone depletion relative to the mid1970s. There was an apparent decline in Arctic ozone during the first two-thirds of the 1990s, but since at that time the halogen loading of the Arctic was already high, such a dramatic decrease in ozone could only arise from dynamical variations (amplified, as noted above, by chemical ozone loss). Indeed, during that period there was a series of cold winters and a near absence of stratospheric sudden warmings. In contrast, since 1998 there has been a return to the more usual state of occasional sudden warmings, and very few cold winters. But this is not ozone recovery, simply a change in meteorological conditions. Historical records (Figure 5) show considerable decadal variability in winterspring stratospheric conditions, with apparent trends over 10-20 year timescales that then get reversed, and are presumably just manifestations of low-frequency variability (Labitzke and Kunze 2005).

This different interpretation of the record of Arctic and Antarctic polar ozone is corroborated in studies of the temperature changes attributable to observed ozone changes (Langematz et al. 2003). On radiative grounds, ozone loss should lead to a cooling of the polar lower stratosphere and a delayed breakdown of the polar vortex. In the Antarctic, this is seen in observations and is well accounted for by climate models forced by the observed ozone changes. In the Arctic, on the other hand, the observed cooling (at least to 2000 , the latest for which studies are available) is much greater than can be explained by the ozone changes; the latter are too little and occur too late in the 
season. This of course makes physical sense, because the cooling is required to initiate the ozone loss and thus cannot be entirely the result of it.

The low-frequency fluctuations in total ozone seen especially in the Northern Hemisphere make the detection and attribution of ozone depletion a challenge. In particular, the fluctuations may project on the trends and thus be misrepresented as the result of halogen loading. The extent of this projection will depend on how the trends are modeled, and the uncertainties in the trends will depend on how the noise is modeled (Vyushin et al. 2007). This is illustrated by Figure 6, which compares the total ozone trends versus latitude over 1979-1995 estimated from observations based on a fit to EESC with those based on a fit to a piecewise linear trend (PWLT) with a turning point in early 1996. The choice of trend model makes essentially no difference in the Southern Hemisphere, but the PWLT-based trend is about 50\% larger than the EESC-based trend in the Northern Hemisphere. One way to assess the robustness of these estimates is to examine their sensitivity to the time period chosen. While PWLT-based trends are notoriously sensitive to the choice of end dates, the EESC-based trends are relatively insensitive (see Figure 14 of Fioletov 2007).

Figure 6 also compares the uncertainties in the trends obtained from different assumptions concerning the autocorrelations of the residuals: namely the conventional first-order autoregressive [AR(1)] model, versus a long-range correlated (LRC) model in which the autocorrelations decay only algebraically rather than exponentially in time. The latter model should take better account of the existence of strong serial correlations (longterm memory). We consider the EESC-based trend (Figure 6a) because it seems likely to be the more accurate one. In the Southern Hemisphere, the two estimates of the trend 
uncertainty are very similar. However in Northern Hemisphere midlatitudes, the LRCbased uncertainty is about 50\% larger than the AR(1)-based uncertainty, with the lower end of the $95 \%$ confidence interval below 0.3 DU/year and approaching zero at the highest latitudes.

All this has important implications when comparing climate simulations against the past. If the observed "trend" was partly the result of natural variability, then it cannot be expected to agree with the mean of an ensemble of simulations. In fact, as discussed in more detail in Section 5, chemistry-climate models tend to underestimate the extent of the observed ozone depletion in the Northern Hemisphere (Austin et al. 2003; Eyring et al. 2006). While this could also be for other reasons (e.g. poor representation of PSC formation), a poor quantification of natural variability remains a strong possibility. Low-frequency fluctuations will likewise confound the detection of ozone recovery. In Northern Hemisphere midlatitudes, total ozone has been increasing strongly since the mid-1990s (see Figure 7 of Fioletov 2007). The increase is much greater than can be explained by the declining halogen loading, and is attributed instead to decadal changes in transport associated with meteorological variability (Yang et al. 2005, Dhomse et al. 2006). [Note that if the PWLT-based trends are to be believed, then a statistically significant increase in total ozone would be on the verge of being detected in Northern Hemisphere midlatitudes (Vyushin et al. 2007), which flies in the face of our physical understanding of ozone recovery.] This behaviour is yet another manifestation of the prominent decadal-scale variability that is characteristic of the Northern Hemisphere stratosphere (see also Figure 5), which means that the Northern Hemisphere is not a good place to detect recovery of total ozone (Vyushin et al. 2007). In contrast, the Southern 
Hemisphere has well-defined trends with tight uncertainties (Figure 6), and earlier predictions that the Southern Hemisphere high midlatitudes would be the optimal place to detect ozone recovery (Weatherhead et al. 2000) have been confirmed by the LRC-based analysis (Vyushin et al. 2007).

\section{Effect of climate change on stratospheric ozone}

Climate change affects stratospheric ozone in two principal ways. The first is through insitu changes within the stratosphere, from radiative-chemical mechanisms, associated with the changes in anthropogenic greenhouse gases (for the stratosphere, this is mainly from the changes in carbon dioxide). The second is through changes in stratospheric wave forcing and hence in the Brewer-Dobson circulation which result from changes in tropospheric climate. That the latter has the potential to be a significant contributor is evident from the contrast between the two hemispheres in the current climate, which results from differences in wave forcing. Whilst in the real atmosphere these two processes occur together and cannot be isolated, in a model they can be. In doubled- $\mathrm{CO}_{2}$ experiments with chemistry-climate models, Sigmond et al. (2004) separated the two processes by doubling $\mathrm{CO}_{2}$ separately in the troposphere and the stratosphere, while Schmidt et al. (2006) and Fomichev et al. (2007) instead did so by separately doubling $\mathrm{CO}_{2}$ and making the corresponding changes to sea surface temperatures and the associated sea ice distributions (SSTs, for short). These approaches are essentially equivalent, since if SSTs are held fixed, tropospheric temperatures hardly change even in the presence of doubled $\mathrm{CO}_{2}$. (Instead, the fixed SSTs act as a heat sink for the troposphere.) In all these cases, the modeled SSTs were obtained from transient 
simulations with coupled atmosphere-ocean models (without stratospheric ozone chemistry).

These studies all found that, at least to a first approximation, the intrinsic radiative-chemical response of the stratosphere to doubled $\mathrm{CO}_{2}$ and the dynamical response were additive. Clear evidence of non-additivity was only found in the vicinity of the tropical tropopause (Fomichev et al. 2007). This suggests that, in the present level of understanding, it is useful to discuss the two effects separately — not least because while the former should be robust, the latter can be expected to be model-dependent and nonrobust.

Increased $\mathrm{CO}_{2}$ is expected to cool the stratosphere, with the cooling greatest for the highest temperatures and thus in the upper stratosphere, and such cooling is well documented in observations (Ramaswamy et al. 2001; see also Figure 3 of McFarlane 2007). The stratosphere is close to being in global-mean radiative equilibrium (e.g. Fomichev et al. 2002), since dynamical effects on temperature cancel out in the global mean - roughly, adiabatic warming in one location must be cancelled by adiabatic cooling somewhere else, by mass conservation — and so the global-mean temperature provides a clean diagnostic for attribution. While there has also been a contribution to upper stratospheric cooling from ozone depletion, model studies have shown that roughly half the global-mean cooling observed since 1980 in the upper stratosphere can be attributed to $\mathrm{CO}_{2}$ increases (Shine et al. 2003). As discussed by McConnell (2007), the $\mathrm{CO}_{2}$-induced upper stratospheric cooling acts to increase ozone abundance in that region. This can be expected to be a robust response to climate change, which has acted to mitigate upper stratospheric ozone depletion from halogens in the past, and will 
accelerate ozone recovery in the future when the two effects of increasing $\mathrm{CO}_{2}$ and decreasing halogens will be acting in concert (Shepherd and Jonsson 2007).

In the lower stratosphere, in contrast, past global-mean temperature changes are mainly attributable to ozone changes (Shine et al. 2003). In this region, the direct effect of $\mathrm{CO}_{2}$ increases on temperature is much smaller than in the upper stratosphere, and has not yet been discernible (see also Langematz et al. 2003). In any case, close to the tropopause the effect of increased $\mathrm{CO}_{2}$ changes from a cooling to a warming (see McFarlane 2007). Thus the main impact of climate change in the lower stratosphere is expected to be felt through changes in the wave-driven circulation, which will be different in different latitude bands.

One reasonably robust response to climate change appears to be an increase in the strength of the upwelling just above the tropical tropopause (Butchart et al. 2006; Fomichev et al. 2007). The change is clearly associated with an increase in wave forcing, but it has yet to be determined exactly which waves are involved. Moreover the strength of the response varies widely in the models examined by Butchart et al. (2006), and there is a rather significant contribution (roughly one-third) from parameterized wave drag or dissipation mechanisms. It is possible that this increased upwelling is entirely associated with waves that break in the subtropical lower stratosphere, and is thus unconnected with the deep Brewer-Dobson circulation that is driven by planetary-wave drag in the stratospheric surf zone. Similar versions of these models were inconsistent in their predictions of changes to the Northern Hemisphere planetary-wave forcing relevant to Arctic temperatures, with some models showing an increase and some a decrease (Austin et al. 2003). 
There has been considerable interest in the possibility that the dynamical response to climate change could affect the Arctic stratosphere. Because the Arctic lower stratosphere lies close to the threshold for widespread PSC formation, relatively small changes could potentially have a significant impact on ozone during the next few decades while the halogen loading remains high. An early study by Shindell et al. (1998) suggested the development of an Arctic ozone hole rivaling that of the Antarctic, in the 2010-2020 time frame, as a result of climate change. However the result was not reproduced by later, more sophisticated models (Austin et al. 2003), and it was concluded by WMO (2003) that the Shindell et al. (1998) result was unphysical. One major challenge in predicting the impact of climate change on the Arctic stratosphere is the manifest presence of decadal-timescale variability (Labitzke and Kunze 2005). This variability is also present in climate models, and means that single realizations, even over many decades, are not robust (Butchart et al. 2000). To make matters worse, standard ttests which assume each year is independent may not identify this non-robustness. For example, Fomichev et al. (2007) found that one 15-year simulation found a cooling at the 95\% significance level in the Arctic wintertime lower stratosphere in response to doubled $\mathrm{CO}_{2}$, but another simulation with exactly the same set-up did not.

There are two distinct issues here. One is that we do not yet know how to properly quantify natural variability in the Arctic stratosphere. Distributions of variables are highly skewed and often very non-Gaussian (Yoden et al. 2002), and the rather unstable behaviour of past decadal trends (Labitzke and Kunze 2005) suggests the presence of serial correlations. Yet the statistics from the rather limited record of observations that exists in the stratosphere are likely not sufficient to define either the distributions or the 
strength of serial correlations. Until recently the statistics have not been sufficient from the models either, since chemistry-climate models were rarely run for more than a few decades, and usually with only one realization. (Fortunately, this is now beginning to change.) This means that many model results were likely not reproducible, and that the comparison with observations was not well founded. There is furthermore a second issue, namely that even when a statistically reliable signal from a model is found, it might be highly sensitive to details of the model formulation (e.g. spatial resolution or gravitywave drag parameters) and thus non-robust in a broader physical sense. However this is largely a problem that still awaits us.

\section{Chemistry-climate model simulations of past and future stratospheric ozone}

For the latest WMO/UNEP Ozone Assessment (WMO 2007), a chemistry-climate model intercomparison was performed under the auspices of the SPARC CCMVal project (Eyring et al. 2005a), using reference simulations defined by Eyring et al. (2005b). This represents the most comprehensive attempt yet to define the impact of climate change on the past and future evolution of stratospheric ozone. The models were validated with process-oriented diagnostics and compared against past observations in Eyring et al. (2006), and then used to make projections of future ozone abundance in Eyring et al. (2007). The discussion here will highlight the main findings of the latter study, using results from the Canadian Middle Atmosphere Model (CMAM) for illustration. (All these CMAM results are shown in Eyring et al. (2007) in the context of the other models.) It was demonstrated in Eyring et al. (2006) that CMAM was representative of the halfdozen most reliable models. However, of those models CMAM was the only one run out 
to 2100 with an ensemble of (three) simulations. Each ensemble member was forced with a different sea-surface temperature and sea-ice time series, taken from an ensemble of coupled atmosphere-ocean simulations performed with the CCCma Global Climate Model on which the CMAM is based, using essentially the same forcing scenario. In this way, we seek to capture a realistic amount of natural variability within the ensemble.

Over the last 25-30 years, stratospheric ozone has declined from the increase in anthropogenic halogens, while the stratosphere has also been affected by climate change. Over the next century, the expected slow removal of anthropogenic halogens from the stratosphere should lead to a recovery of stratospheric ozone, but the climate change will continue. It is thus interesting to contrast the two periods. By the end of the century, there should be no discernible effects of halogens and the differences from the pre-1970 period will be purely the result of climate change.

All the models were forced with the Ab halogen scenario of WMO (2003) although, as McConnell (2007) discusses, there was not complete consistency in how the source gases were specified. Nevertheless a striking result of Eyring et al. (2006) was how much spread there was in the abundance of inorganic chlorine $\left(\mathrm{Cl}_{\mathrm{y}}\right)$ in the model stratospheres. In order to obtain the correct amount of stratospheric $\mathrm{Cl}_{\mathrm{y}}$ from the tropospheric source gases, especially in the critical lower stratosphere polar regions, a model requires a reasonable representation of transport: in particular a correct BrewerDobson circulation, a correct degree of polar vortex isolation, and a realistic age of air. There was a cluster of a half-dozen models with fairly similar $\mathrm{Cl}_{\mathrm{y}}$, which increased through the 1980s and 1990s as expected and more or less in line with observations (Figure 7b). These models also exhibited realistic distributions of age of air (Figure 7a), 
albeit with a slight young bias which explains why the model $\mathrm{Cl}_{\mathrm{y}}$ peaks at slightly too low a value (Newman et al. 2006). Another half-dozen models (shown in the dashed lines in Figure 7) exhibited widely different $\mathrm{Cl}_{\mathrm{y}}$, for a variety of reasons ranging from nonconservation in model transport, to a too-low model lid which does not allow a correct representation of the Brewer-Dobson circulation nor of the photochemical aging necessary to obtain realistic $\mathrm{Cl}_{\mathrm{y}}$ levels. The transport problems in these models were also reflected in other diagnostics such as age of air. Eyring et al. (2007) showed that the single greatest factor in the projected future return of global ozone abundance to pre-1980 levels was a model's representation of the $\mathrm{Cl}_{\mathrm{y}}$ loading. Thus, only those models with physically reasonable $\mathrm{Cl}_{\mathrm{y}}$ loading were deemed to provide reliable estimates of the future evolution of stratospheric ozone.

It has to be said that even those latter models are somewhat underpredicting the time taken for $\mathrm{Cl}_{\mathrm{y}}$ to return to pre-1980 levels, because of their young age-of-air bias (Newman et al. 2006). The models predict Antarctic springtime lower stratospheric $\mathrm{Cl}_{\mathrm{y}}$ to return to 1980 levels during 2040-2050, whereas an empirical prediction based on observed age of air (Newman et al. 2006) puts the date in the range 2060-2070. Since the models all seem to indicate a decrease in age of air in the future, the most likely date (for the Ab scenario) probably lies somewhere in between.

We first consider the temperature evolution. Figure 8 shows the global-mean temperature trend in CMAM as a function of altitude, for the 1980-1999 and the 20002049 time periods. The vertical profile of the trend exhibits a notably different shape in the two time periods, as the contribution of ozone depletion during 1980-1999 changes to that of ozone recovery (albeit at a slower rate) in 2000-2049. In particular, the cooling 
trend in the upper stratosphere (where the modeled global ozone depletion was by far the largest, in terms of mixing ratio) is much reduced during the latter time period. However in the middle stratosphere, where the ozone trends have been much weaker, the cooling trend increases in the latter period. Figure 9(a) shows the time evolution of the globalmean temperature at $50 \mathrm{hPa}$ for CMAM, with the ERA-40 reanalysis also provided for the past evolution (but only since the introduction of satellite observations in 1979, to minimize data inhomogeneity problems). Apart from the warm spikes in the reanalysis temperatures, which are associated with volcanic eruptions not represented in the simulations, both model and reanalysis show a continuous cooling in the past, which the model predicts to modestly strengthen in the future. The past cooling appears to be somewhat underpredicted by the model. (Although one should always be wary of using reanalysis products to derive trends, the global-mean ERA-40 timeseries at $50 \mathrm{hPa}$ over this period is consistent with the RATPAC radiosonde data (Eyring et al., 2006).)

Dynamical effects on temperature can show up in trends over sub-global regions. Figures 9(b) and 9(c) show the temperature time series for CMAM and for ERA-40 at 50 $\mathrm{hPa}$ for the two polar regions during late winter. By considering the trends in this part of the year, cooling from ozone depletion should not be a significant factor. In the Arctic, CMAM exhibits no evident change in the past, with considerable variability. While the extent of the observed cooling is not reproduced, an important question is whether the latter is really deterministic, given that the variability in the past observations is so great (and bearing in mind Figure 5). This likely cannot be answered from the observations alone. In the future, the CMAM Arctic appears to exhibit a slow warming. Given the global-mean cooling at $50 \mathrm{hPa}$, this warming must reflect an increased planetary-wave 
drag and associated downwelling. Such an effect does seem to be characteristic of many current CCMs (e.g. Austin et al. 2003), but has yet to be well quantified and may not be robust.

In the Antarctic, CMAM shows a definite cooling in the past which is consistent with the observed cooling. Therefore in contrast to the Arctic, the observed cooling in the Antarctic late-winter lower stratosphere appears to be a deterministic signal. In the future, CMAM exhibits a continued cooling which is slightly stronger than the global and annual-mean cooling, suggesting a possible weakening of the planetary-wave drag and associated downwelling, at least at high latitudes. If it turns out that the dynamical response to climate change is actually opposite in the two polar regions, this would be quite interesting and would help to explain why it has been so difficult to identify a robust dynamical response in these regions.

Turning now to ozone, Figure 10 shows the time evolution of total ozone over various latitude bands in CMAM from 1960-2100, together with that of $\mathrm{Cl}_{\mathrm{y}}$ at $50 \mathrm{hPa}$. The observations are shown from 1964 to present. It is seen that CMAM near-global $\left(60^{\circ} \mathrm{S}-60^{\circ} \mathrm{N}\right)$ total ozone declines by about $4 \%$ between 1970 and 2000 , and then increases by about $4 \%$ from 2000 to the end of the $21^{\text {st }}$ century. The past decline is similar in magnitude to that seen in the observations, but it is notable that the observed decline has occurred since about 1980, while CMAM (as with many CCMs) shows some ozone decline during the 1970s. CMAM near-global ozone reaches its 1980 levels just before 2040, at the same time as CMAM Cl $\mathrm{y}_{\mathrm{y}}$ reaches its 1980 levels; so for this diagnostic, ozone is controlled by $\mathrm{Cl}_{\mathrm{y}}$ and there is no evidence of any effect of climate change. The fact that CMAM near-global ozone exceeds 1980 values at the end of the 
$21^{\text {st }}$ century is not "super-recovery" but simply a reflection of the fact that in CMAM, 1980 ozone levels were already suffering from ozone depletion.

However the near-global picture shown in Figure 10(a) contains somewhat different behaviour in the tropics and extratropics. In the tropics (Figure 10(b)), CMAM total ozone declines about $3 \%$ by 2000 , but remains about $2 \%$ below 1960 values at the end of the century; while in midlatitudes (Figures 10(c) and 10(d)), in both hemispheres but especially so in the Northern Hemisphere, CMAM total ozone exceeds early values by the end of the century. These differences point to a strengthened Brewer-Dobson circulation in CMAM, which is corroborated in a steadily decreasing age of air (D. Plummer, personal communication, 2006).

The main discrepancy between the simulated and observed total ozone changes is found in the tropics. However, since 1979 the stratospheric ozone column in the tropics has declined by about 7-8 DU, or about 3\% (Randel and Wu 2007), a value which is very consistent with the CMAM total ozone decline shown in Figure 10(b). (Allowing for this would also bring the observed near-global total ozone decline in Figure 10(a) more in line with the CMAM value.) Note that this version of CMAM does not simulate tropospheric chemistry. The discrepancy between the observed stratospheric and total column changes is not resolved (Randel and Wu 2007), but it is certainly conceivable that tropical tropospheric ozone could have increased during the last 25 years, thereby masking the stratospheric ozone decline in the total column.

Figure 11 shows the vertical distribution of ozone changes in CMAM, in various regions and seasons, between 1960-1970 and 2070-2099. As both periods are characterized by essentially unperturbed levels of halogens in CMAM (see Figure 10), 
the ozone changes reflect the effects of climate change. (These periods are different from those used in Eyring et al. (2007) for a similar plot, whose choice was restricted by the limited period of the simulation for some of the models.) As the changes are shown in units of DU/km, equal areas contribute approximately equal amounts. It is seen that in all panels ozone increases substantially in the upper stratosphere, as the expected result of the $\mathrm{CO}_{2}$-induced cooling in this region. In the lower stratosphere, global-mean ozone decreases. Part of this is undoubtedly the "reverse self-healing" that results from increased ozone in the upper stratosphere, but there will also be an effect from the circulation changes discussed above, as (unlike with temperature) these do not necessarily cancel out in the global mean. The lower stratospheric decrease is quite pronounced in the tropics, while in midlatitudes there is an increase, especially in the Northern Hemisphere, supporting the inference of an increased Brewer-Dobson circulation (at least in the lower stratosphere). It is notable that one-half of the observed decrease in tropical stratospheric ozone has come from altitudes below $25 \mathrm{~km}$ (Randel and $\mathrm{Wu}$ 2007), providing additional confidence in this aspect of the CMAM response to climate change.

Finally, we consider springtime polar ozone in CMAM. Figures 11(e) and 11(f) show the vertical profiles of ozone changes in the two hemispheres between 1960-1970 and 2070-2099, while Figure 12 shows the time evolution of minimum springtime polar total ozone over the entire 1960-2100 period. In the Arctic, like essentially all CCMs (Eyring et al. 2007), CMAM does not reproduce the observed record of Arctic minimum total ozone, including the very low years in the late 1990s. However, the observed record is characterized by enormous interannual variability, and does not exhibit a clear trend 
over the last 25 years. This mirrors the earlier discussion concerning Arctic temperature trends. The fact that CMAM does not simulate the very coldest Arctic winters, with the most severe ozone depletion, may well be a dynamical bias, in that this version of CMAM has no QBO and instead exhibits persistent tropical easterlies. In light of the Holton-Tan mechanism discussed earlier, one might expect that persistent tropical easterlies would tend to reduce the likelihood of very cold winters. It is also quite possible that CMAM's representation of PSC formation and heterogeneous chemistry (which ignores the possibility of denitrification) does not allow enough chemical ozone loss, although this effect is most likely trumped by the dynamical issues. In the future, CMAM Arctic springtime ozone reaches higher levels than in the past. This is consistent with the higher Arctic late-winter temperatures seen in Figure 9(b), which imply a strengthened polar downwelling and hence greater transport of ozone to high latitudes. Figure 11(e) shows that this ozone increase occurs mainly below $30 \mathrm{hPa}$, with a maximum below $100 \mathrm{hPa}$.

In the Antarctic, CMAM (like most CCMs) follows the observed development of the ozone hole quite well. It is notable that in CMAM, the ozone hole begins to develop in the early 1970s, and has achieved fully half its eventual magnitude by 1980 . This is actually quite consistent with the Halley observations (Figure 1.5 of IPCC/TEAP 2005). In the future, Antarctic ozone does not quite recover to pre-1970 values by the end of the century, which is consistent with the apparent decrease in polar downwelling inferred from the temperature changes (Figure 9(c)), together with the stronger transport barrier implied by a colder vortex. Figure 11(f) shows that this ozone decrease occurs mainly below $30 \mathrm{hPa}$, with a maximum around $100 \mathrm{hPa}$. Accordingly, Antarctic ozone in 
CMAM returns to 1980 values (which as already noted does not correspond to full ozone recovery) in the 2060-2070 time period, later than the date at which $\mathrm{CMAM} \mathrm{Cl}_{\mathrm{y}}$ returns to 1980 levels.

Note that one potential factor which has received a lot of attention in the scientific literature is the possible increase of stratospheric water vapour as a result of climate change. Increased water vapour would lead to radiative cooling in the lower stratosphere and to enhanced formation of PSCs, both of which would tend to aggravate ozone depletion while halogen loading remains high. Interest in this possibility was fuelled by an apparent observed trend of rapidly increasing stratospheric water vapour, far greater than could be explained by increased methane abundance or any change in tropical dehydration (SPARC 2000). However more recent observations have suggested a considerably different picture (Randel et al. 2004), with stratospheric water vapour decreasing since about 2000. While the observed record is still not fully explained, interannual water vapour changes appear to be largely explainable by variations in tropical tropopause temperature (Randel et al. 2004). Moreover the most recent CCM simulations show only a modest increase in water vapour (Eyring et al. 2007).

\section{Summary and discussion}

Ever since the discovery of the ozone hole, dynamics has played an important role in understanding the nature and phenomenology of stratospheric ozone depletion. At first the questions primarily revolved around the role of dynamics in shaping and modulating chemical ozone loss. Subsequently, researchers turned their attention to the role of dynamical effects in explaining aspects of the long-term variations in observed ozone 
abundance. With stratospheric halogen loading now slowly declining, the questions are evolving to the detection of the onset of ozone recovery and the prediction of the future state of the ozone layer, within the broader context of climate change. In particular, there is a policy need to distinguish and separately attribute the effects of ozone-depleting substances and greenhouse gases on ozone and climate (recognizing that they are in many ways coupled).

In the context of tropospheric climate change, global climate models (GCMs) have proven to be essential tools in the detection, attribution and prediction of global warming. The counterpart of GCMs for stratospheric ozone are chemistry-climate models (CCMs). While CCMs have been under development for well over a decade, it is fair to say that they have only recently emerged as useful tools in the assessment of ozone changes. This development is mainly due to two factors, both of which are the direct result of steadily increasing computational capability: the ability to run models with sufficiently high spatial resolution (and model lid heights) to achieve realistic age of air, and the ability to routinely perform multi-decadal simulations and thus begin to provide ensembles of simulations. The CCMVal activity for SPARC (Eyring et al. 2005a) is coordinating the assessment and use of CCMs for understanding and predicting changes in stratospheric ozone, by developing process-oriented diagnostics to serve as key metrics of model performance, and defining simulation protocols. Already CCMVal provided a key contribution to the $2006 \mathrm{WMO} / \mathrm{UNEP}$ Ozone Assessment (Chapter 6 of WMO 2007).

Part of the assessment of CCMs involves a comparison with past observations (Eyring et al. 2006), which immediately raises the question of which aspects of past 
behaviour should be able to be captured by the CCMs. This is forcing a reassessment of how well we understand the observed changes in stratospheric ozone. Answering this question will require a good quantitative understanding of stratospheric dynamical variability, especially on the longer (e.g. decadal) timescales. Models will almost certainly be required for this analysis, partly because of the shortness of the observed record, and partly because statistical analysis of observations is almost invariably ambiguous in terms of causality (as illustrated by Figure 3). However since the models themselves need to have their variability validated, this is a challenging exercise.

A broad overview of our current level of understanding of past and future ozone changes (and the role of dynamics in these changes) can be obtained by summarizing the CMAM results for global and polar ozone discussed in Section 5, as they are representative of the results from the half-dozen most reliable CCMs, but provide the only ensemble extending from 1960-2100 (Eyring et al. 2007).

In CMAM, near-global total ozone $\left(60^{\circ} \mathrm{S}-60^{\circ} \mathrm{N}\right)$ declines in line with the halogen increases, by approximately the observed magnitude of about $4 \%$, and is predicted to also recover in line with the expected future halogen decline. While future global ozone levels are predicted to exceed 1980 values, CMAM suggests that the 1980 atmosphere was already experiencing ozone depletion, and does not provide any evidence of long-term "super-recovery". Rather, the increase in upper stratospheric ozone expected from $\mathrm{CO}_{2}$ induced cooling is approximately cancelled by a decrease in the lower stratosphere. The apparent discrepancy with observations, which show no evidence of a global ozone decline prior to 1980 , is unexplained, but a quantitative assessment of the statistical significance of this discrepancy has not yet been made. CMAM also suggests a 
strengthening Brewer-Dobson circulation due to climate change, which tends to decrease total ozone in the tropics and to increase it in the sub-polar extratropics, especially in the Northern Hemisphere. These circulation-induced changes in ozone occur mainly in the lowest part of the stratosphere, and lead to a long-term "dynamical super-recovery" in total ozone of about $4 \%$ above 1960 values in northern midlatitudes. The CMAM midlatitude total ozone declines in the past are quite consistent with the observed changes. While observed column ozone in the tropics does not reflect the decline of about $3 \%$ seen in CMAM, the observed stratospheric column decline is quite consistent with the CMAM value. Thus, the CMAM simulations paint a consistent picture of extra-polar ozone changes that are driven by a combination of changes in halogen loading (leading to a maximum total-ozone decline of $4 \%$ over $60^{\circ} \mathrm{S}-60^{\circ} \mathrm{N}$ ) and a strengthened BrewerDobson circulation associated with climate change, and which appear to be consistent with the observed changes.

In the Arctic, observations of both ozone and temperature show strong decadalscale variability and it is difficult to isolate a clear long-trend. CMAM does not reproduce the extent of past Arctic ozone losses, but while the model may certainly be deficient, it is also quite possible that the past behaviour may not be deterministic. In the future, CMAM suggests a dynamically induced warming of the Arctic stratosphere and associated transport-related ozone increase from climate change. In the Antarctic, the development of the ozone hole and the associated cooling represents a clear signal, which CMAM is able to reproduce. In the future, CMAM predicts a recovery of Antarctic ozone more or less in line with the decrease in halogen loading, but slightly delayed by an apparent 
dynamically induced cooling and associated transport-related ozone decrease from climate change.

For dynamicists, a principal challenge in the near future will be to gain a better quantitative understanding of dynamical variability in the stratosphere, in order to provide more accurate statistical comparisons between models and observations (and between the models themselves), and a better understanding of the uncertainties in future predictions - bearing in mind that the real atmosphere will only exhibit a single realization. The recent availability of ensembles of long model simulations (such as those shown here) should allow significant progress to be made in this respect. For this purpose it is critical that CCM groups devote sufficient computational resources to produce ensembles of long simulations, otherwise their results will be of limited value. At the same time, it needs to be recognized that CCMs are likely to have significant systematic errors in their variability (e.g. associated with the absence of a QBO, or a cold-pole bias, or deficiencies in the tropospheric climate), which certainly need to be borne in mind and ultimately addressed.

Even after the statistical issues have been settled, a remaining major challenge for dynamicists is to gain a better understanding of the robustness of predicted dynamical changes (such as circulation changes) to model specifications such as resolution, model lid height, and physical parameterizations. For example, it has been shown that the circulation change induced by the gravity-wave-drag response to a stratospheric radiative change (e.g. the ozone hole) depends sensitively on model lid height when momentum is not conserved in the gravity-wave-drag parameterization — as is generally the case in practice - but is robust to changes in model lid height when momentum is conserved 
(Shaw and Shepherd 2007). More generally, however, this issue of model robustness is a wide open area and will require a concerted effort to address.

In terms of more technical matters, we can look forward to developments on three fronts over the next few years. First, CCMs will start to be coupled to full ocean models. Such a configuration will allow a far more self-consistent assessment of the effects of stratospheric changes (including ozone changes) on the troposphere, because both the sea-surface temperatures and ozone distribution will be determined consistently, not imposed from another model. Second, the stratospheric chemistry in CCMs will start to be extended into the troposphere. This will provide much more convincing representations of global tropospheric chemistry in climate models, which hitherto have had significant uncertainties associated with the flux of ozone from the stratosphere. Third, CCMs will likely also be extended into the mesosphere, to provide a more realistic representation of the effects of solar variability and particle precipitation on ozone and climate. All three developments will provide exciting opportunities for new research, in which dynamical effects will play a central role.

Acknowledgements: The generous assistance of David Plummer in producing the CMAM figures is very gratefully acknowledged. Michaela Hegglin, David Plummer and Dmitry Vyushin provided helpful comments. The author's research is supported by the Natural Sciences and Engineering Research Council of Canada, the Canadian Foundation for Climate and Atmospheric Sciences, and the Canadian Space Agency. The Canadian Middle Atmosphere Model is supported by these agencies as well as by Environment Canada. 


\section{References}

Austin, J., D. Shindell, S.R. Beagley, C. Brühl, M. Dameris, E. Manzini, T. Nagashima, P. Newman, S. Pawson, G. Pitari, E. Rozanov, C. Schnadt and T.G. Shepherd, 2003: Uncertainties and assessments of chemistry-climate models of the stratosphere. Atmos. Chem. Phys., 3, 1-27.

Baldwin, M.P., et al., 2001: The Quasi-Biennial Oscillation. Rev. Geophys., 39, 179-229.

Bodeker, G.E., H. Shiona and H. Eskes, 2005: Indicators of Antarctic ozone depletion. Atmos. Chem. Phys., 5, 2603-2615.

Butchart, N., J. Austin, J.R. Knight, A.A. Scaife and M.L. Gallani, 2000: The response of the stratospheric climate to projected changes in the concentrations of well-mixed greenhouse gases from 1992 to 2051. J. Clim., 13, 2142-2159.

Butchart, N., et al., 2006: Simulations of anthropogenic change in the strength of the Brewer-Dobson circulation. Clim. Dyn., 27, 727-741.

Dhomse, S., M. Weber, I. Wohltmann, M. Rex and J.P. Burrows, 2006: On the possible causes of recent increases in northern hemispheric total ozone from a statistical analysis of satellite data from 1979 to 2003. Atmos. Chem. Phys., 6, 1165-1180.

Eyring, V., et al., 2005a: A strategy for process-oriented validation of coupled chemistry-climate models. Bull. Amer. Met. Soc., 86, 1117-1133.

Eyring, V., D.E. Kinnison and T.G. Shepherd, 2005b: Overview of planned coupled chemistry-climate simulations to support upcoming ozone and climate assessments. SPARC Newsletter, No. 25, pp. 11-17. 
Eyring, V., et al., 2006: Assessment of coupled chemistry-climate models: Evaluation of dynamics, transport characteristics and ozone. J. Geophys. Res., 111, D22308, doi: 10.1029/2006JD007327.

Eyring, V., et al., 2007: Multi-model projections of stratospheric ozone in the $21^{\text {st }}$ century. J. Geophys. Res., 112, in press, 10.1029/2006JD008332.

Fioletov, V.E., 2007: Ozone climatology, trends, and substances that control ozone. (This issue.)

Fioletov, V.E., G.E. Bodeker, A.J. Miller, R.D. McPeters and R. Stolarski, 2002: Global and zonal total ozone variations estimated from ground-based and satellite measurements: 1964-2000. J. Geophys. Res., 107, 4647.

Fioletov, V.E. and T.G. Shepherd, 2003: Seasonal persistence of midlatitude total ozone anomalies. Geophys. Res. Lett., 30, 1417, doi: 10.1029/2002GL016739.

Fioletov, V.E. and T.G. Shepherd, 2005: Summertime total ozone variations over middle and polar latitudes. Geophys. Res. Lett., 32, L04807, doi: 10.1029/2004GL022080.

Fomichev, V.I., W.E. Ward, S.R. Beagley, C. McLandress, J.C. McConnell, N.A. McFarlane and T.G. Shepherd, 2002: The extended Canadian Middle Atmosphere Model: Zonal-mean climatology and physical parameterizations. J. Geophys. Res., 107, 4087, 10.1029/2001JD000479.

Fomichev, V.I., A.I. Jonsson, J. de Grandpré, S.R. Beagley, C. McLandress, K. Semeniuk and T.G. Shepherd, 2007: Response of the middle atmosphere to $\mathrm{CO}_{2}$ doubling: Results from the Canadian Middle Atmosphere Model. J. Clim., 20, 1121-1144.

Fusco, A.C. and M.L. Salby, 1999: Interannual variations of total ozone and their relationship to variations of planetary wave activity. J. Clim., 12, 1619-1629. 
Gray, L.J., S.A. Crooks, M.A. Palmer, C.L. Pascoe and S. Sparrow, 2006: A possible transfer mechanism for the 11-year solar cycle to the lower stratosphere. Space Sci. Rev., 125, 357-370.

Hadjinicolaou, P., J.A. Pyle, M.P. Chipperfield and J.A. Kettleborough, 1997: Effect of interannual meteorological variability on mid-latitude ozone. Geophys. Res. Lett., 24, 2993-2996.

Haynes, P.H., 2005: Stratospheric dynamics. Ann. Rev. Fluid Mech., 37, 263-293.

Holton, J.R. and H.-C. Tan, 1980: The influence of the equatorial quasi-biennial oscillation on the global circulation at 50 mb. J. Atmos. Sci., 37, 2200-2208.

IPCC/TEAP, 2005: Special Report on Safeguarding the Ozone Layer and the Global Climate System: Issues Related to Hydrofluorocarbons and Perfluorocarbons. Cambridge University Press, 488 pp.

Labitzke, K. and M. Kunze, 2005: Stratospheric temperatures over the Arctic: Comparison of three data sets. Meteorol. Z., 14, 65-74.

Langematz, U., M. Kunze, K. Krüger, K. Labitzke and G.L. Roff, 2003: Thermal and dynamical changes of the stratosphere since 1979 and their link to ozone and $\mathrm{CO}_{2}$ changes. J. Geophys. Res., 108, 4027, doi: 10.1029/2002JD002069.

Manney, G.L., N.J. Livesey, C.J. Jimenez, H.C. Pumphrey, M.L. Santee, I.A. MacKenzie and J.W. Waters, 2006: EOS Microwave Limb Sounder observations of "frozen-in" anticyclonic air in Arctic summer. Geophys. Res. Lett., 33, L06810, doi: 10.1029/2005GL025418.

McConnell, J.C., 2007: Ozone atmospheric chemistry. (This issue) 
McFarlane, N.A., 2007: Stratospheric ozone and climate: Radiative forcing and responses. (This issue)

Newman, P.A., J.F. Gleason, R.D. McPeters and R.S. Stolarski, 1997: Anomalously low ozone over the Arctic. Geophys. Res. Lett., 24, 2689-2692.

Newman, P.A., E.R. Nash and J.E. Rosenfield, 2001: What controls the temperature of the Arctic stratosphere during the spring? J. Geophys. Res., 106, 19999-20010.

Newman, P.A., E.R. Nash, S.R. Kawa, S.A. Montzka and S.M. Schauffler, 2006: When will the Antarctic ozone hole recover? Geophys. Res. Lett., 33, L12814, doi: 10.1029/2005GL025232.

Orsolini, Y.J., 2001: Long-lived tracer patterns in the summer polar stratosphere. Geophys. Res. Lett., 28, 3855-3858.

Pendlebury, D. and T.G. Shepherd, 2003: Planetary-wave-induced transport in the stratosphere. J. Atmos. Sci., 60, 1456-1470.

Plumb, R.A., 2002: Stratospheric transport. J. Meteor. Soc. Japan, 80, 793-809.

Ramaswamy, V., et al., 2001: Stratospheric temperature trends: Observations and model simulations. Rev. Geophys., 39, 71-122.

Randel, W.J., F. Wu and R. Stolarski, 2002: Changes in column ozone correlated with the stratospheric EP flux. J. Meteor. Soc. Japan, 80, 849-862.

Randel, W.J., F. Wu, S.J. Oltmans, K. Rosenlof and G.E. Nedoluha, 2004: Interannual changes of stratospheric water vapor and correlations with tropical tropopause temperatures. J. Atmos. Sci., 61, 2133-2148. 
Randel, W.J. and F. Wu, 2007: A stratospheric ozone profile data set for 1979-2005: Variability, trends, and comparisons with column ozone data. J. Geophys. Res., 112, D06313, doi: 10.1029/2006JD007339.

Rex, M., R.J. Salawitch, P. von der Gathen, N.R.P. Harris, M.P. Chipperfield and B. Naujokat, 2004: Arctic ozone loss and climate change. Geophys. Res. Lett., 31, L04116, doi: 10.1029/2003GL018844.

Schmidt, H., et al., 2006: The HAMMONIA chemistry climate model: Sensitivity of the mesopause region to the 11-year solar cycle and $\mathrm{CO}_{2}$ doubling. J. Clim., 19, 39033931.

Scott, R.K. and P.H. Haynes, 1998: Internal interannual variability of the extratropical stratospheric circulation: The low-latitude flywheel. Quart. J. Roy. Meteor. Soc., 124, 2149-2173.

Semeniuk, K. and T.G. Shepherd, 2001: Mechanisms for tropical upwelling in the stratosphere. J. Atmos. Sci., 58, 3097-3115.

Shaw, T.A. and Shepherd, T.G., 2007: Angular momentum conservation and gravity wave drag parameterization: Implications for climate models. J. Atmos. Sci., 64, $190-203$.

Shepherd, T.G., 2000: The middle atmosphere. J. Atmos. Solar-Terres. Phys., 62, 15871601.

Shepherd, T.G., 2002: Issues in stratosphere-troposphere coupling. J. Meteor. Soc. Japan, 80, 769-792.

Shepherd, T.G., 2003: Large-scale atmospheric dynamics for atmospheric chemists. Chem. Reviews, 103, 4509-4531. 
Shepherd, T.G., 2007: Transport in the middle atmosphere. J. Meteor. Soc. Japan, 85B, $165-191$.

Shepherd, T.G. and A.I. Jonsson, 2007: On the attribution of stratospheric ozone and temperature changes to changes in ozone-depleting substances and well-mixed greenhouse gases. Atmos. Chem. Phys., submitted.

Shepherd, T.G., R.A. Plumb and S.C. Wofsy, 2005: Preface to JAS Special Issue on the Antarctic Stratospheric Sudden Warming and Split Ozone Hole of 2002. J. Atmos. Sci., 62, 565-566.

Shindell, D.T., D. Rind and P. Lonergan, 1998: Increased polar stratospheric ozone losses and delayed eventual recovery owing to increasing greenhouse-gas concentrations. Nature, 392, 589-592.

Shine, K.P., et al., 2003: A comparison of model-simulated trends in stratospheric temperatures. Quart. J. Roy. Meteor. Soc., 129, 1565-1588.

Sigmond, M., P.C. Siegmund, E. Manzini and H. Kelder, 2004: A simulation of the separate climate effects of middle-atmospheric and tropospheric $\mathrm{CO}_{2}$ doubling. $J$. Clim., 17, 2352-2367.

SPARC, 2000: SPARC Assessment of Upper Tropospheric and Stratospheric Water Vapour, SPARC Report No. 2, 312 pp.

Stenchikov, G., K. Hamilton, A. Robock, V. Ramaswamy and M.D. Schwarzkopf, 2004: Arctic oscillation response to the 1991 Pinatubo eruption in the SKYHI general circulation model with a realistic quasi-biennial oscillation. J. Geophys. Res., 109, D03112, doi: 10.1029/2003JD003699. 
Tegtmeier, S. and T.G. Shepherd, 2007: Persistence and photochemical decay of springtime total ozone anomalies in the Canadian Middle Atmosphere Model. Atmos. Chem. Phys., 7, 485-493.

Vyushin, D.I., V.E. Fioletov and T.G. Shepherd, 2007: Impact of long-range correlations on trend detection in total ozone. J. Geophys. Res., 112, D14307, 10.1029/2006JD008168.

Weatherhead, E.C., et al., 2000: Detecting the recovery of total column ozone. $J$. Geophys. Res., 105, 22201-22210.

Weber, M., S. Dhomse, F. Wittrock, A. Richter, B.M. Sinnhuber and J.P. Burrows, 2003: Dynamical control of $\mathrm{NH}$ and $\mathrm{SH}$ winter/spring total ozone from GOME observations in 1995-2002. Geophys. Res. Lett., 30, 1583, doi: 10.1029/2002GL016799.

WMO, 2003: Scientific Assessment of Ozone Depletion: 2002, Global Ozone Research and Monitoring Project—Report No. 47, World Meteorological Organization.

WMO, 2007: Scientific Assessment of Ozone Depletion: 2006, Global Ozone Research and Monitoring Project—Report No. 50, World Meteorological Organization.

Yang, E.-S., et al., 2006: Attribution of recovery in lower-stratospheric ozone. $J$. Geophys. Res., 111, D17309, doi: 10.1029/2005JD006371.

Yoden, S., M. Taguchi and Y. Naito, 2002: Numerical studies on time variations of the troposphere-stratosphere coupled system. J. Meteor. Soc. Japan, 80, 811-830.

Yulaeva, E., J.R. Holton and J.M. Wallace, 1994: On the cause of the annual cycle in tropical lower stratospheric temperatures. J. Atmos. Sci., 51, 169-174. 


\section{Figure captions}

Figure 1: Long-term observed total ozone trends over 1978-2003, determined by a fit to EESC, in the polar, midlatitude and extratropical regions of each hemisphere. The trend is expressed in Dobson units (DU) per year during the 1980s, when the EESC trend was approximately linear. On that scale, a 1 DU/year trend yields a maximum decline of $\sim 17$ DU in the late 1990s. From Fioletov and Shepherd (2005).

Figure 2: Time series of observed extratropical total ozone anomalies in each hemisphere over each year from 1978 to 2003 . The anomalies are constructed by removing the longterm trend (fit to EESC), and then adding the anomalies back to the EESC fit for the year 2000. Note the different scale in the two panels. From Tegtmeier and Shepherd (2007).

Figure 3: Increase of total ozone over $50^{\circ}-90^{\circ}$ over the winter-spring season as a function of wave forcing, the latter expressed in terms of heat flux (proportional to the vertical component of the Eliassen-Palm flux) at $100 \mathrm{hPa}$ averaged from $40^{\circ}-75^{\circ}$ from autumn through spring. (For the Southern Hemisphere, the heat flux is negative so its absolute value is shown.) The inserts show GOME total ozone for four of the years. Courtesy of Mark Weber, University of Bremen, updated from Weber et al. (2003).

Figure 4: Time series of observed springtime polar ozone, in each hemisphere. Courtesy of Paul Newman, NASA Goddard Space Flight Center, updated from Newman et al. (1997). 
Figure 5: Time series of $30 \mathrm{hPa}$ North Pole temperatures, from the NCEP/NCAR reanalysis, for December (left) and March (right). The straight lines indicate linear trends through the respective time periods. Courtesy of Markus Kunze, Free University of Berlin, updated from Labitzke and Kunze (2005).

Figure 6: Total ozone trends over the period 1979-1995, estimated by a statistical fit over 1979-2005 to (a) EESC and (b) a piecewise linear trend with a turning point in early 1996. The seasonal cycle, QBO and solar variations are first removed from the time series. The 95\% confidence intervals are shown under two alternative assumptions concerning the long-term memory (i.e. serial correlation, or persistence) of the residuals: first-order autoregressive (light grey) and long-range correlated (dark grey). From Vyushin et al. (2007).

Figure 7. Left panel: Mean age of air at $50 \mathrm{hPa}$ from various CCMs, as indicated, together with observational estimates based on $\mathrm{CO}_{2}$ and $\mathrm{SF}_{6}$. Right panel: Time series of October mean Cly concentrations at $50 \mathrm{hPa}$ and $80^{\circ} \mathrm{S}$ from various CCMs, together with observational estimates based on HCl. From Eyring et al. (2006).

Figure 8: Global and annual mean temperature trend from CMAM, averaged over three ensemble members, over 1980-1999 (solid) and 2000-2049 (dashed). Courtesy of David Plummer, Environment Canada. 
Figure 9. Time series of temperature at $50 \mathrm{hPa}$ from CMAM from 1960 through 2100, averaged over (a) $90^{\circ} \mathrm{S}-90^{\circ} \mathrm{N}$ during the entire year, (b) $60^{\circ} \mathrm{N}-90^{\circ} \mathrm{N}$ during JanuaryFebruary, and (c) $60^{\circ} \mathrm{S}-90^{\circ} \mathrm{S}$ during August-September. Anomalies are calculated relative to the 1980-1999 mean. The colour symbols show the individual years for each ensemble member, while the colour lines are the same results smoothed with a Gaussian filter with a width of 8 year. ERA-40 reanalysis data are shown by the black dots. Courtesy of David Plummer, Environment Canada.

Figure 10. Time series of deseasonalized monthly mean total ozone anomalies from CMAM for $1960-2100$, averaged over (a) $60^{\circ} \mathrm{S}-60^{\circ} \mathrm{N}$, (b) $25^{\circ} \mathrm{S}-25^{\circ} \mathrm{N}$, (c) $35^{\circ} \mathrm{N}-60^{\circ} \mathrm{N}$, and (d) $35^{\circ} \mathrm{S}-60^{\circ} \mathrm{S}$. Anomalies are calculated relative to the $1960-1975$ mean. The gray lines show the time series for each of the three ensemble members, while the black lines show the smoothed anomalies for each run after the application of a Gaussian filter with a width of 8 years. The green lines show the smoothed annual mean $\mathrm{Cl}_{\mathrm{y}}$ anomalies from CMAM at $50 \mathrm{hPa}$, averaged over $60^{\circ} \mathrm{S}-60^{\circ} \mathrm{N}$. Observations (updated from Fioletov et al. 2002) are shown by the red curve, with the anomalies defined relative to the 1964-1975 mean and with the QBO, solar cycle and volcanic effects removed. Courtesy of David Plummer, Environment Canada.

Figure 11. Vertical profile of ozone changes between 1960-1970 and 2070-2099 in CMAM, expressed in terms of DU/km, for different latitude bands and seasons as indicated. The solid line indicates the ensemble mean, the dashed lines the individual ensemble members. Courtesy of David Plummer, Environment Canada. 
Figure 12. Time series of minimum springtime polar ozone from 1960 to 2100 from CMAM, in the (a) Arctic and (b) Antarctic. The colour symbols show the individual years for each ensemble member, while the colour lines are the same results smoothed with a Gaussian filter with a width of 8 year. Observations from Bodeker et al. (2005) are shown by the black dots. Courtesy of David Plummer, Environment Canada. 
Figures (N.B. quality is sometimes degraded by its importation into this Word document)
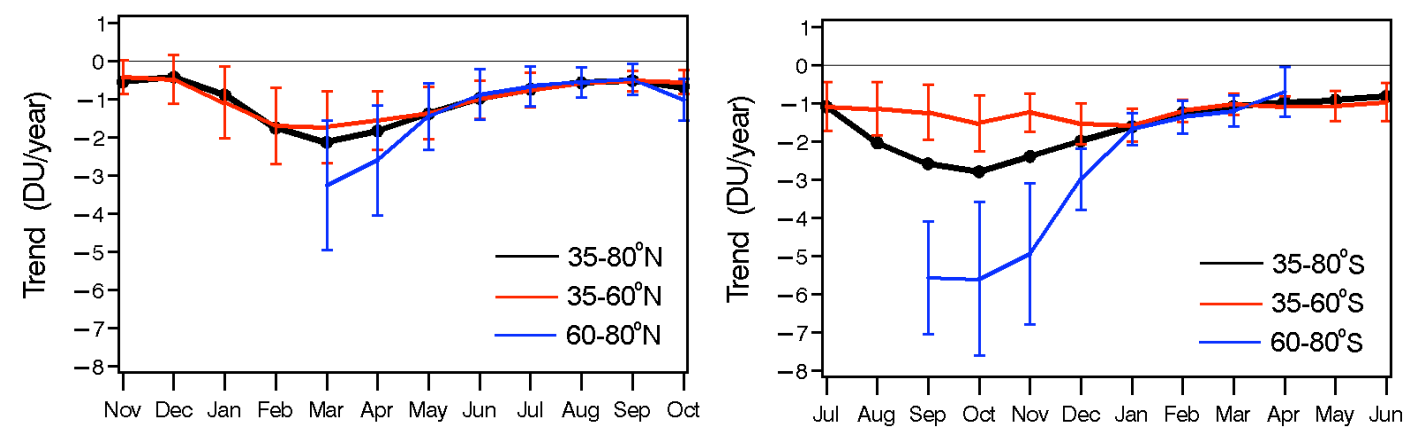

Figure 1: Long-term observed total ozone trends over 1978-2003, determined by a fit to EESC, in the polar, midlatitude and extratropical regions of each hemisphere. The trend is expressed in Dobson units (DU) per year during the 1980s, when the EESC trend was approximately linear. On that scale, a 1 DU/year trend yields a maximum decline of $\sim 17$ DU in the late 1990s. From Fioletov and Shepherd (2005).
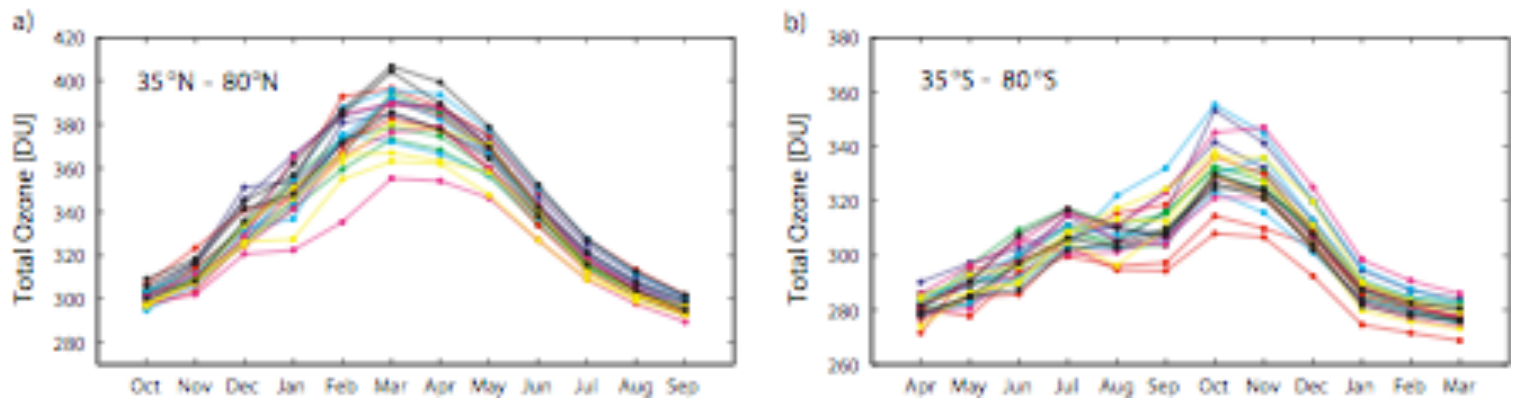

Figure 2: Time series of observed extratropical total ozone anomalies in each hemisphere over each year from 1978 to 2003 . The anomalies are constructed by removing the longterm trend (fit to EESC), and then adding the anomalies back to the EESC fit for the year 2000. Note the different scale in the two panels. From Tegtmeier and Shepherd (2007). 


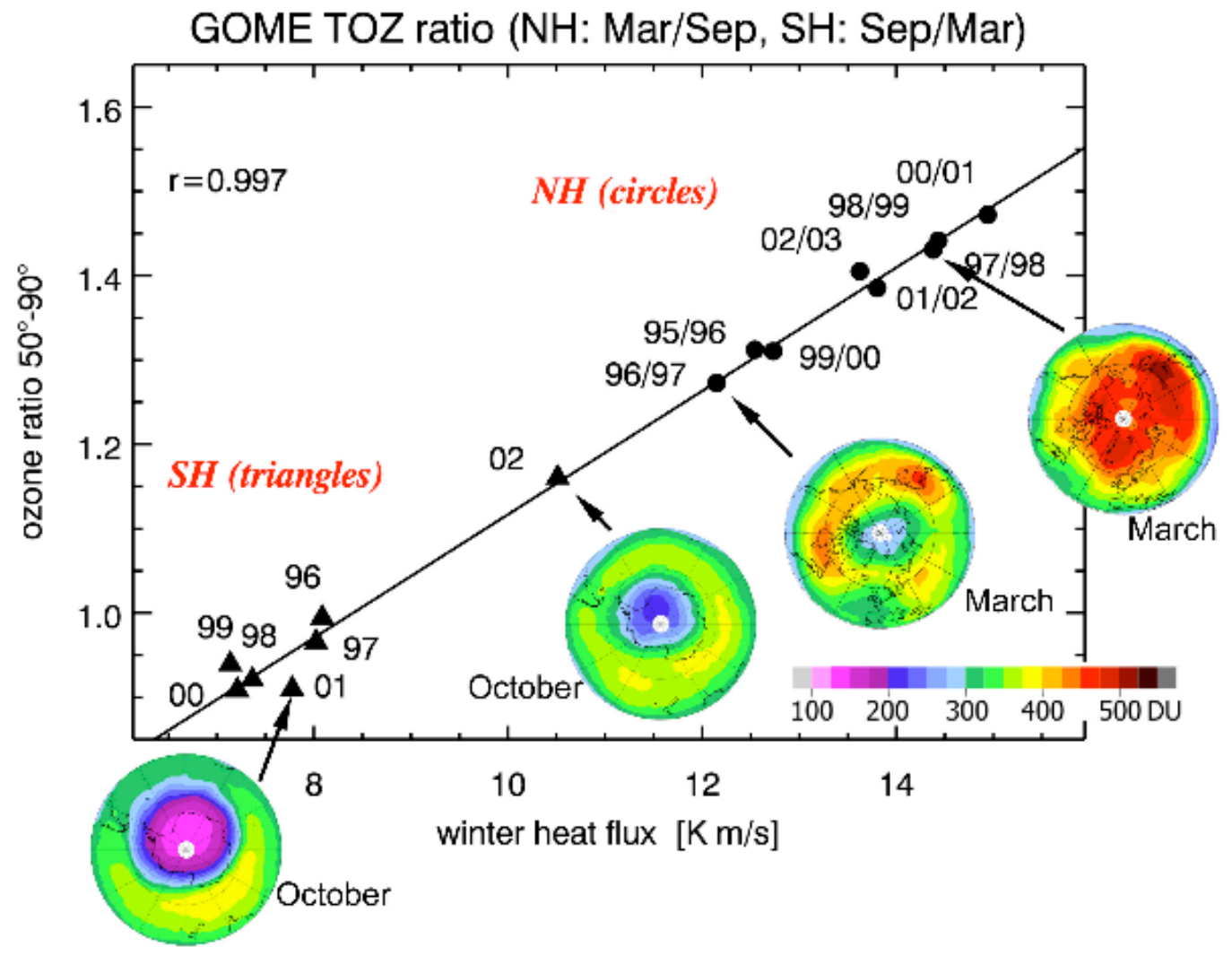

Figure 3: Increase of total ozone over $50^{\circ}-90^{\circ}$ over the winter-spring season as a function of wave forcing, the latter expressed in terms of heat flux (proportional to the vertical component of the Eliassen-Palm flux) at $100 \mathrm{hPa}$ averaged from $40^{\circ}-75^{\circ}$ from autumn through spring. (For the Southern Hemisphere, the heat flux is negative so its absolute value is shown.) The inserts show GOME total ozone for four of the years. Courtesy of Mark Weber, University of Bremen, updated from Weber et al. (2003). 


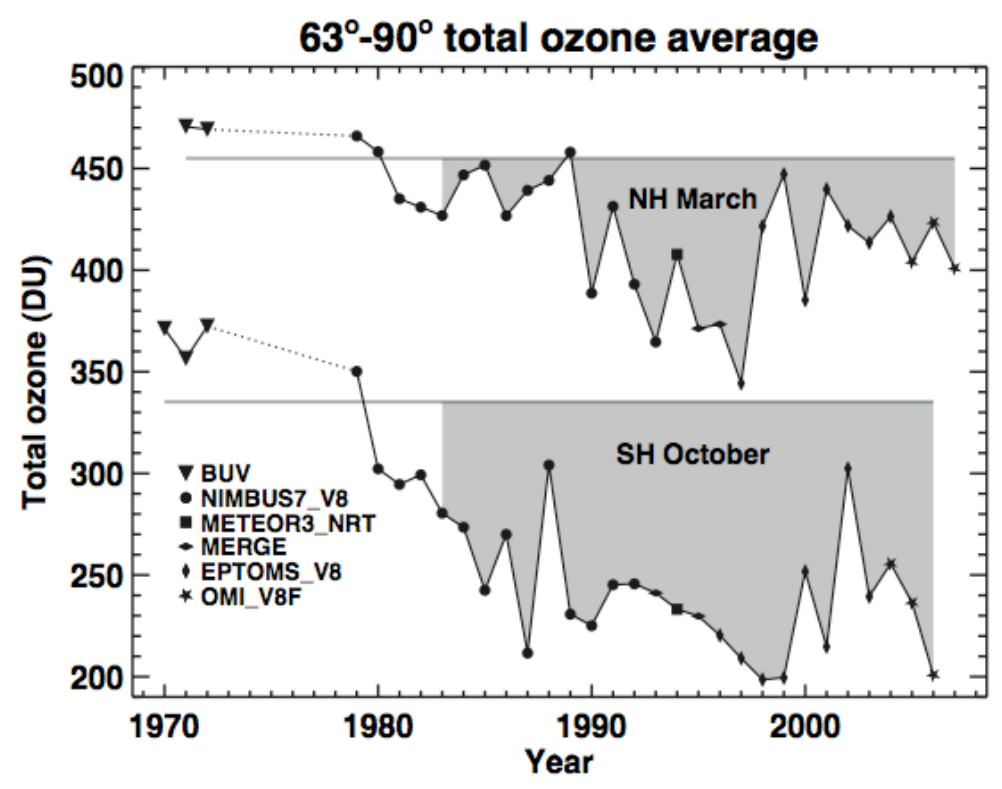

Figure 4: Time series of observed springtime polar ozone, in each hemisphere. Courtesy of Paul Newman, NASA Goddard Space Flight Center, updated from Newman et al. (1997).
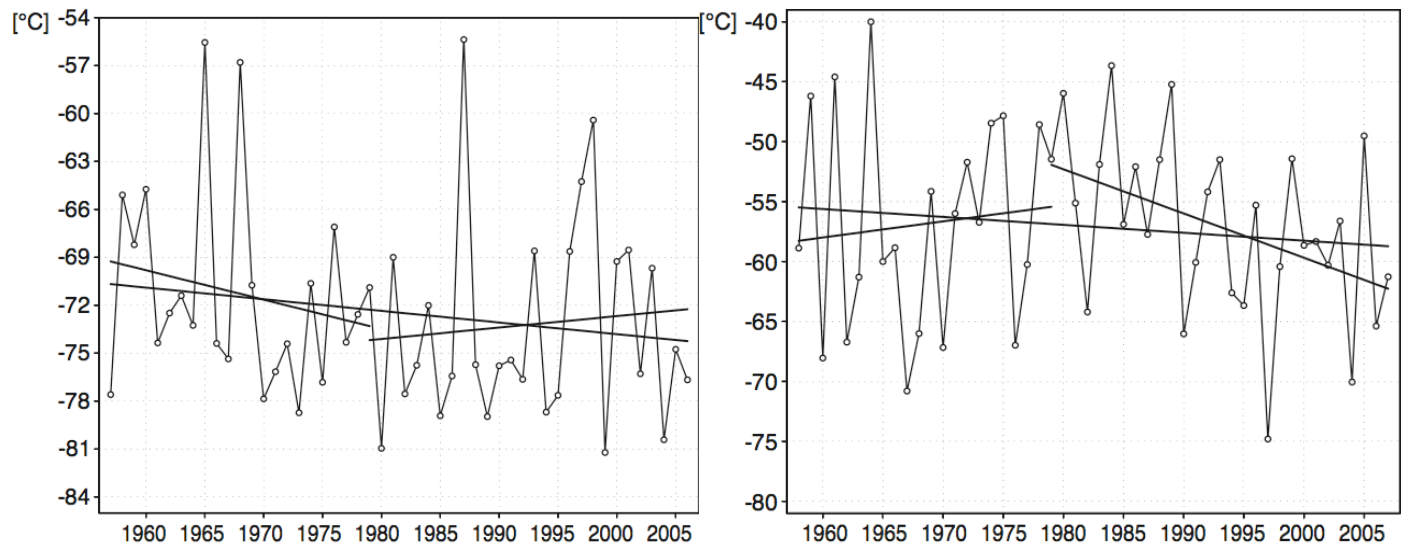

Figure 5: Time series of $30 \mathrm{hPa}$ North Pole temperatures, from the NCEP/NCAR reanalysis, for December (left) and March (right). The straight lines indicate linear trends through the respective time periods. Courtesy of Markus Kunze, Free University of Berlin, updated from Labitzke and Kunze (2005). 

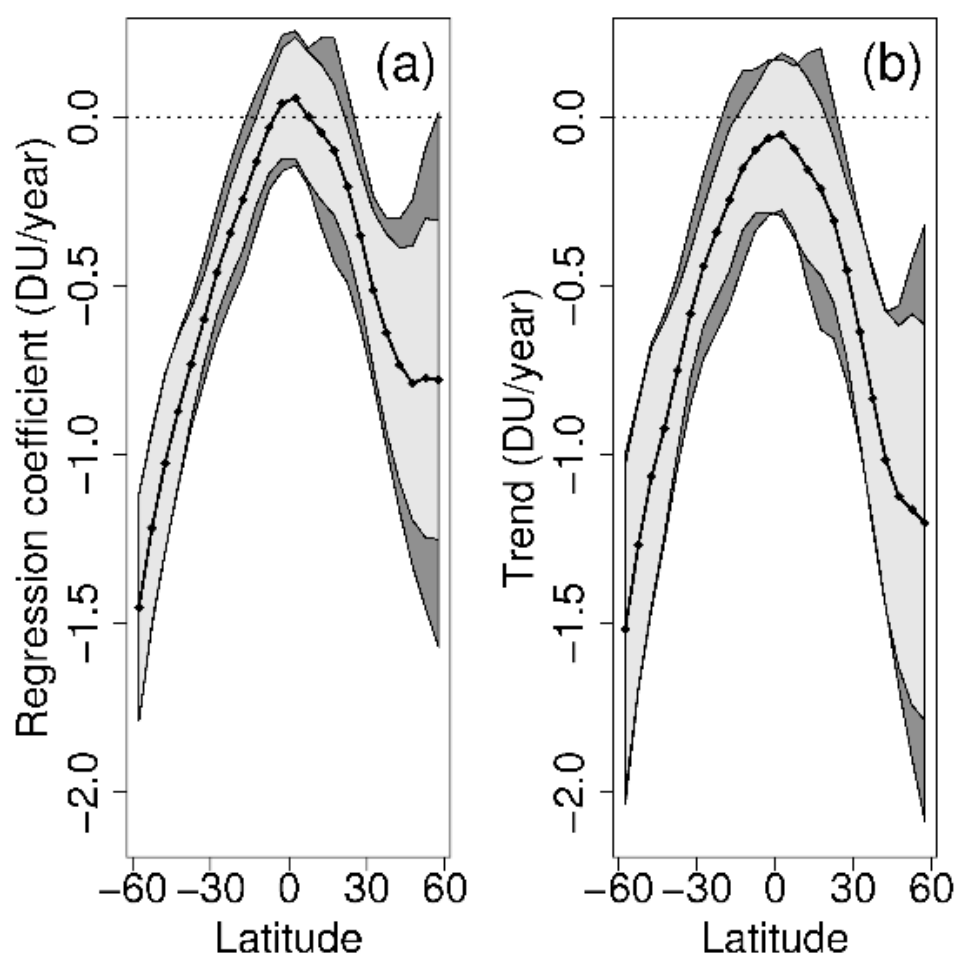

Figure 6: Total ozone trends over the period 1979-1995, estimated by a statistical fit over 1979-2005 to (a) EESC and (b) a piecewise linear trend with a turning point in early 1996. The seasonal cycle, QBO and solar variations are first removed from the time series. The $95 \%$ confidence intervals are shown under two alternative assumptions concerning the long-term memory (i.e. serial correlation, or persistence) of the residuals: first-order autoregressive (light grey) and long-range correlated (dark grey). From Vyushin et al. (2007). 

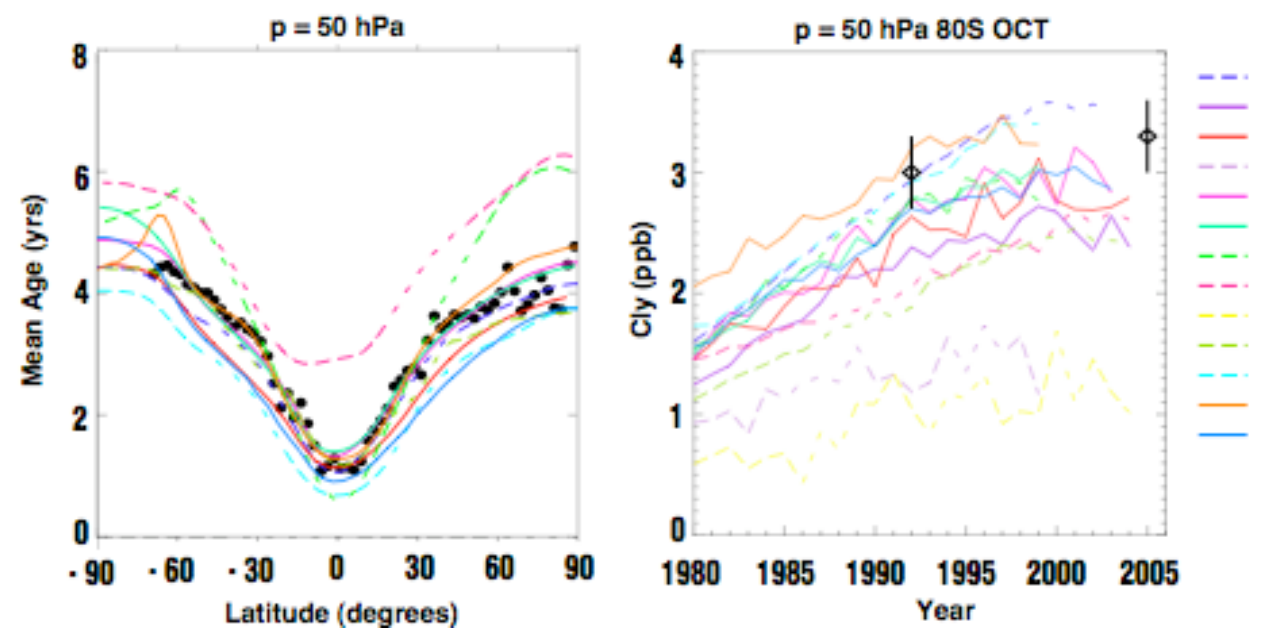

Figure 7. Left panel: Mean age of air at $50 \mathrm{hPa}$ from various CCMs, as indicated, together with observational estimates based on $\mathrm{CO}_{2}$ and $\mathrm{SF}_{6}$. Right panel: Time series of October mean Cly concentrations at $50 \mathrm{hPa}$ and $80^{\circ} \mathrm{S}$ from various $\mathrm{CCMs}$, together with observational estimates based on $\mathrm{HCl}$. From Eyring et al. (2006).

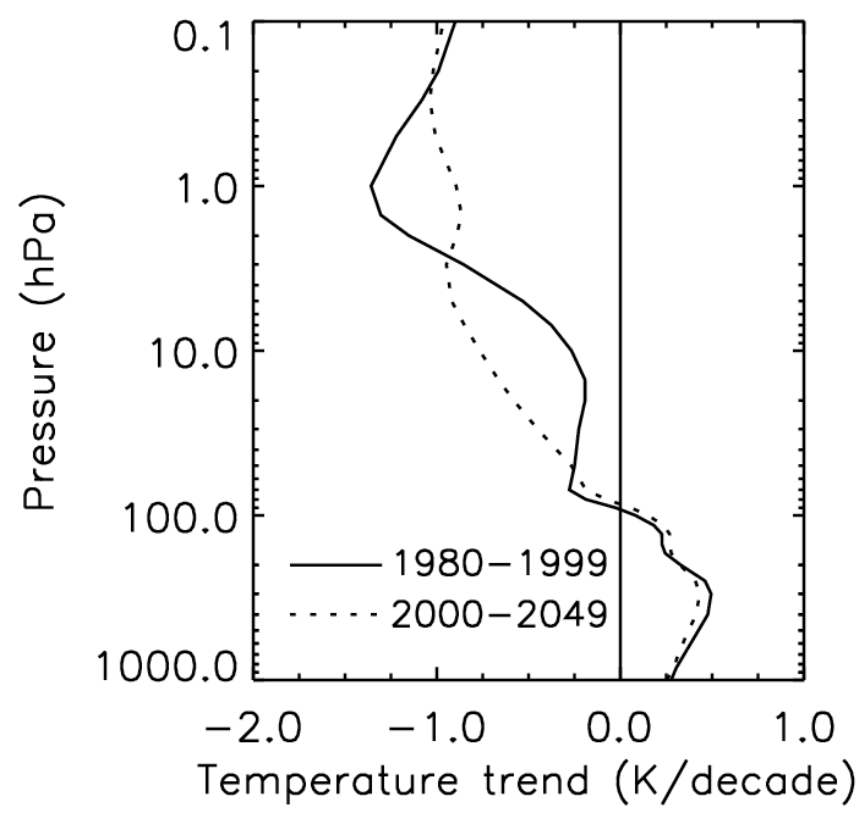

Figure 8: Global and annual mean temperature trend from CMAM, averaged over three ensemble members, over 1980-1999 (solid) and 2000-2049 (dashed). Courtesy of David Plummer, Environment Canada. 

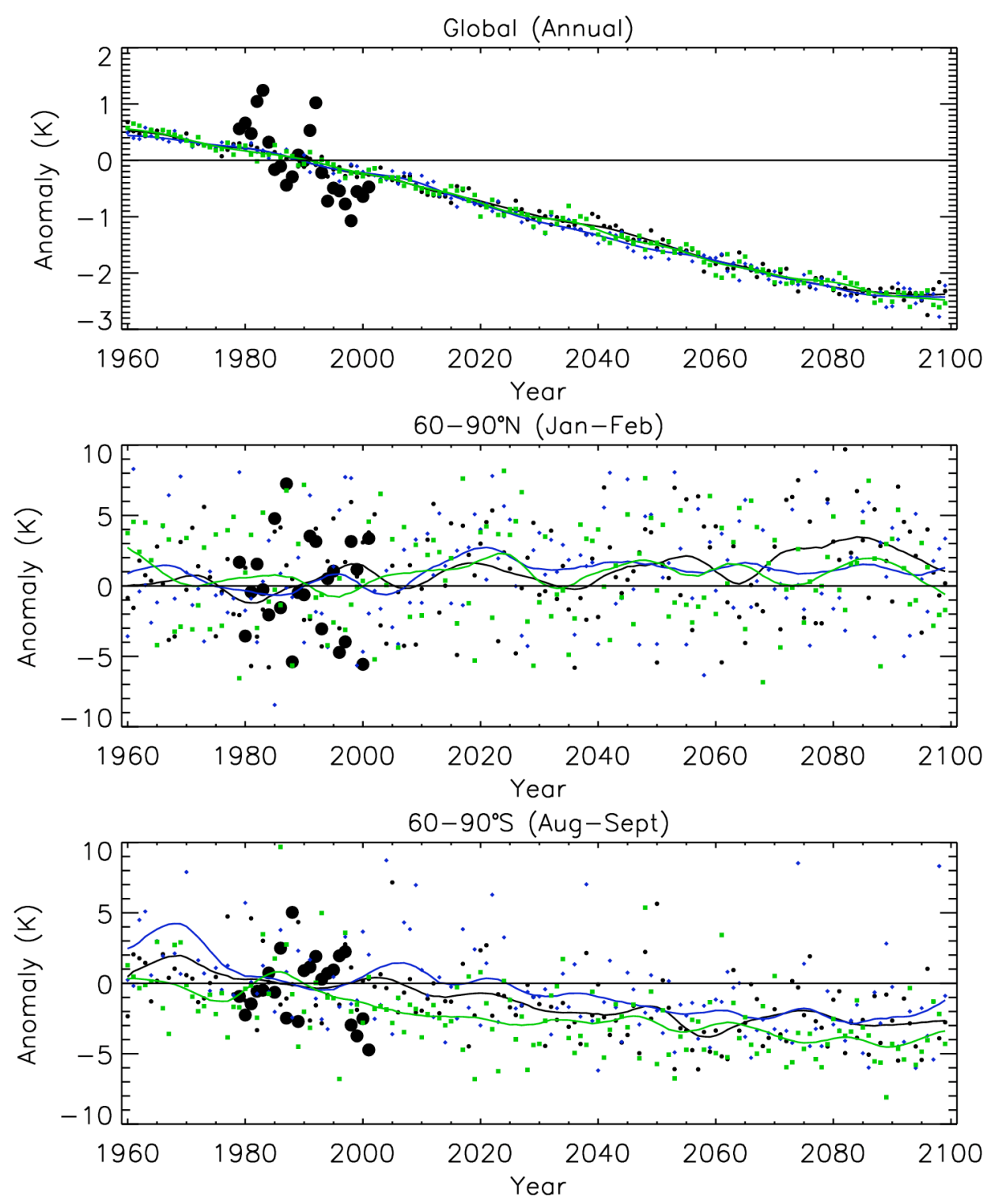

Figure 9. Time series of temperature at $50 \mathrm{hPa}$ from CMAM from 1960 through 2100, averaged over (a) $90^{\circ} \mathrm{S}-90^{\circ} \mathrm{N}$ during the entire year, (b) $60^{\circ} \mathrm{N}-90^{\circ} \mathrm{N}$ during JanuaryFebruary, and (c) $60^{\circ} \mathrm{S}-90^{\circ} \mathrm{S}$ during August-September. Anomalies are calculated relative to the 1980-1999 mean. The colour symbols show the individual years for each ensemble member, while the colour lines are the same results smoothed with a Gaussian filter with a width of 8 year. ERA-40 reanalysis data are shown by the black dots. Courtesy of David Plummer, Environment Canada. 

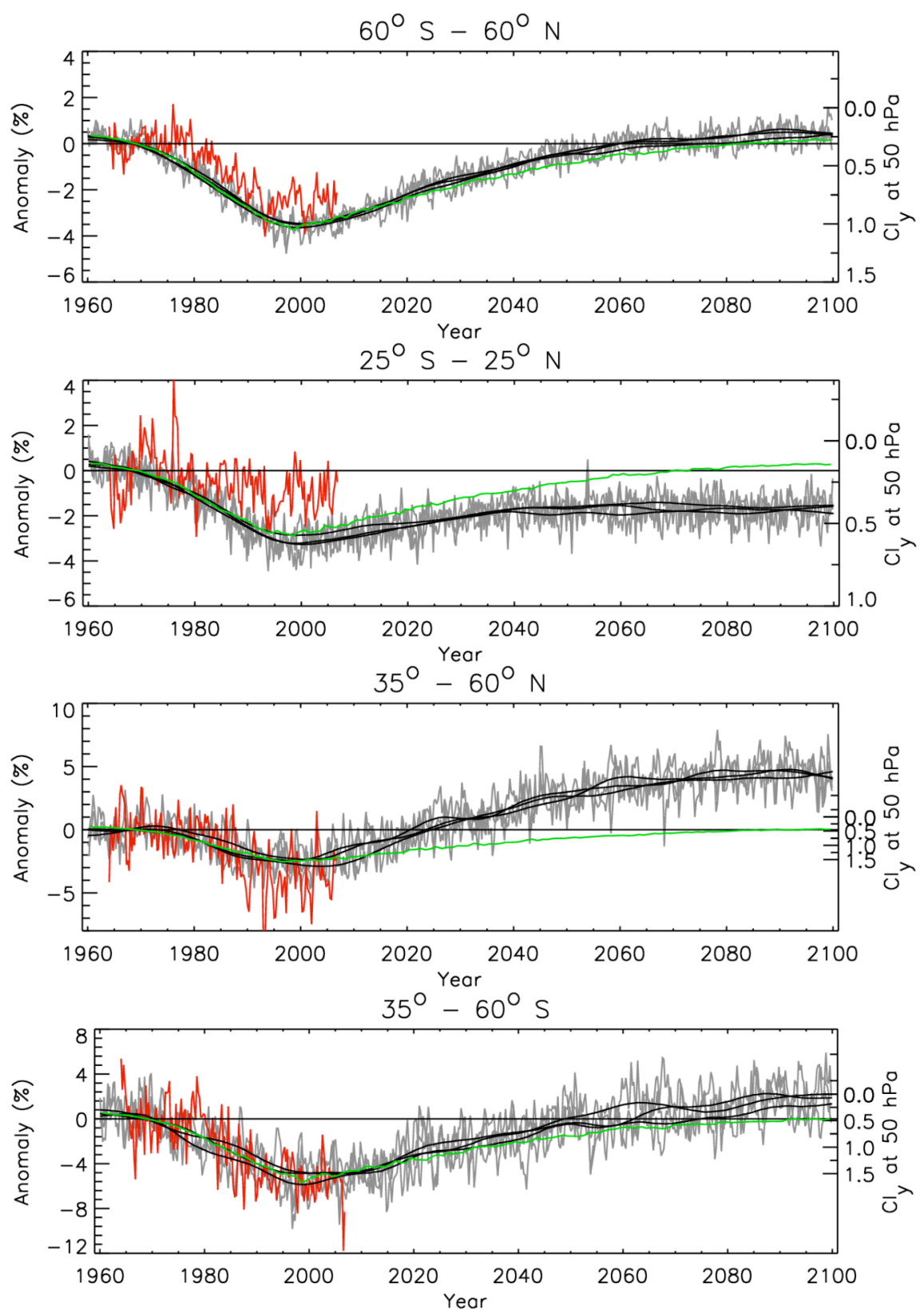

Figure 10. Time series of deseasonalized monthly mean total ozone anomalies from CMAM for $1960-2100$, averaged over (a) $60^{\circ} \mathrm{S}-60^{\circ} \mathrm{N}$, (b) $25^{\circ} \mathrm{S}-25^{\circ} \mathrm{N}$, (c) $35^{\circ} \mathrm{N}-60^{\circ} \mathrm{N}$, and (d) $35^{\circ} \mathrm{S}-60^{\circ} \mathrm{S}$. Anomalies are calculated relative to the $1960-1975$ mean. The gray lines show the time series for each of the three ensemble members, while the black lines show the smoothed anomalies for each run after the application of a Gaussian filter with a width of 8 years. The green lines show the smoothed annual mean $\mathrm{Cl}_{\mathrm{y}}$ anomalies from 
CMAM at $50 \mathrm{hPa}$, averaged over $60^{\circ} \mathrm{S}-60^{\circ} \mathrm{N}$. Observations (updated from Fioletov et al. 2002) are shown by the red curve, with the anomalies defined relative to the 1964-1975 mean and with the QBO, solar cycle and volcanic effects removed. Courtesy of David Plummer, Environment Canada. 
a) Global annual average
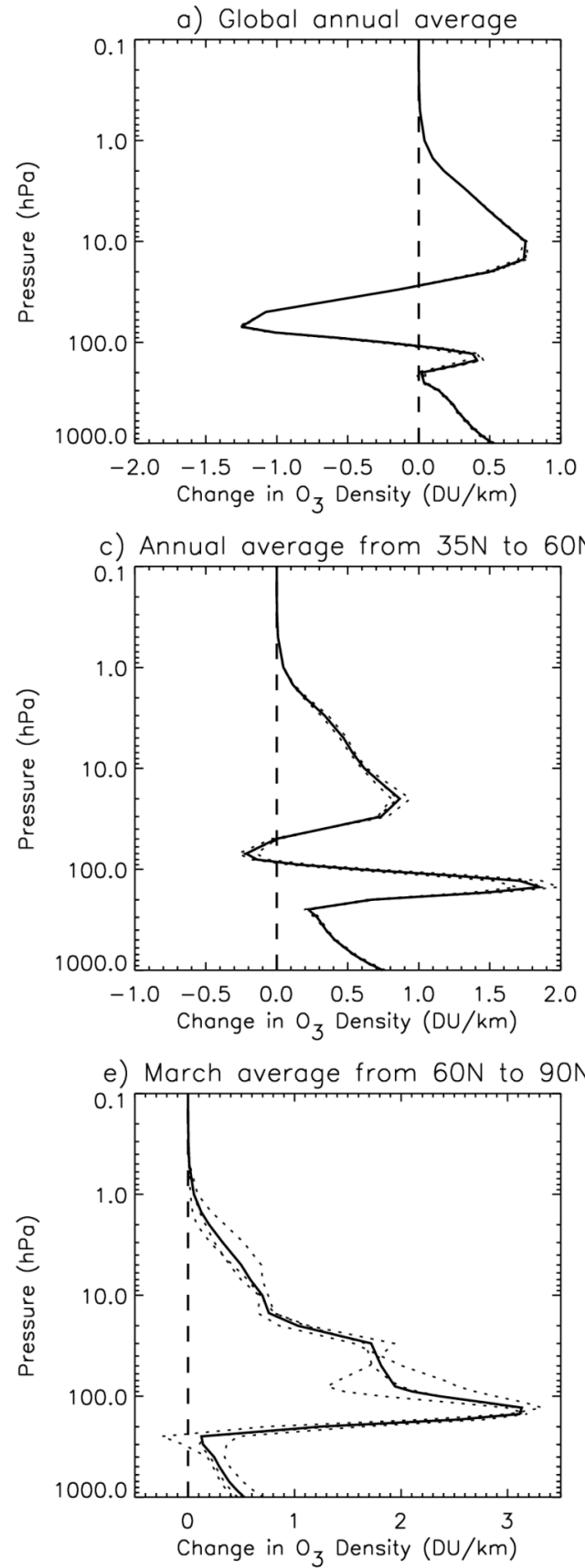

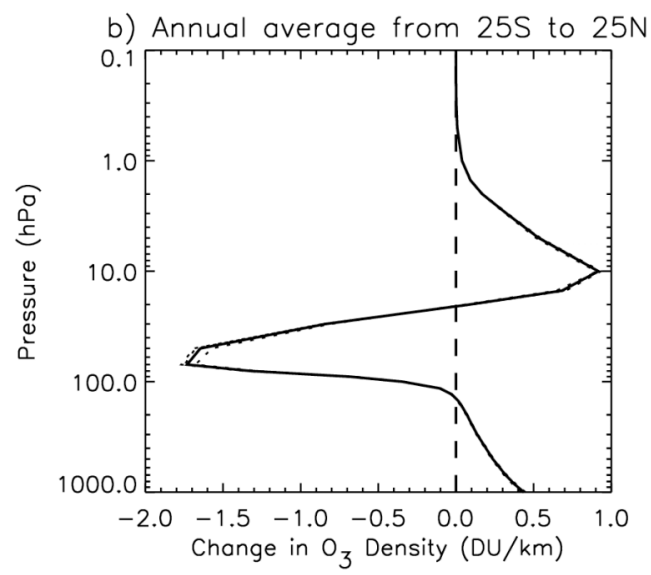

d) Annual average from 355 to $60 \mathrm{~s}$

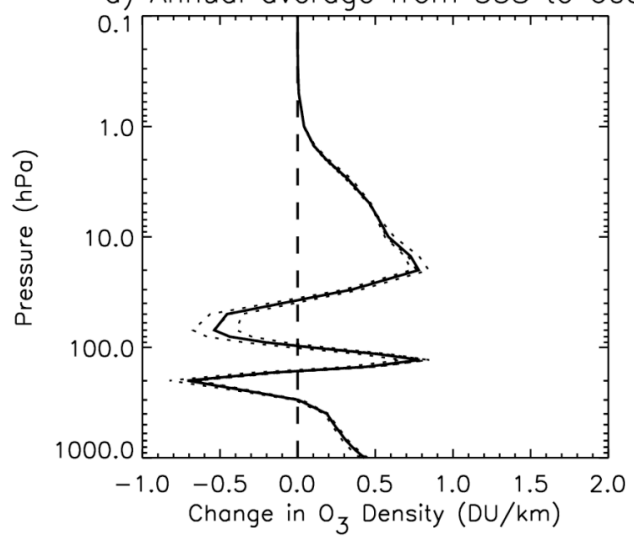

f) October average from 605 to 905

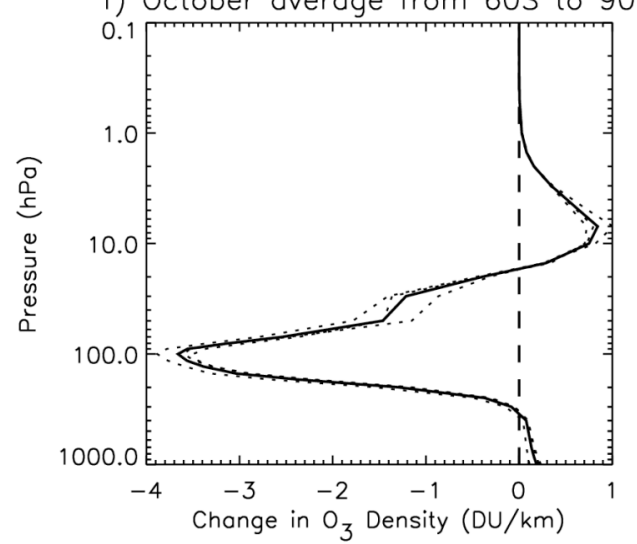

Figure 11. Vertical profile of ozone changes between 1960-1970 and 2070-2099 in CMAM, expressed in terms of DU/km, for different latitude bands and seasons as indicated. The solid line indicates the ensemble mean, the dashed lines the individual ensemble members. Courtesy of David Plummer, Environment Canada. 

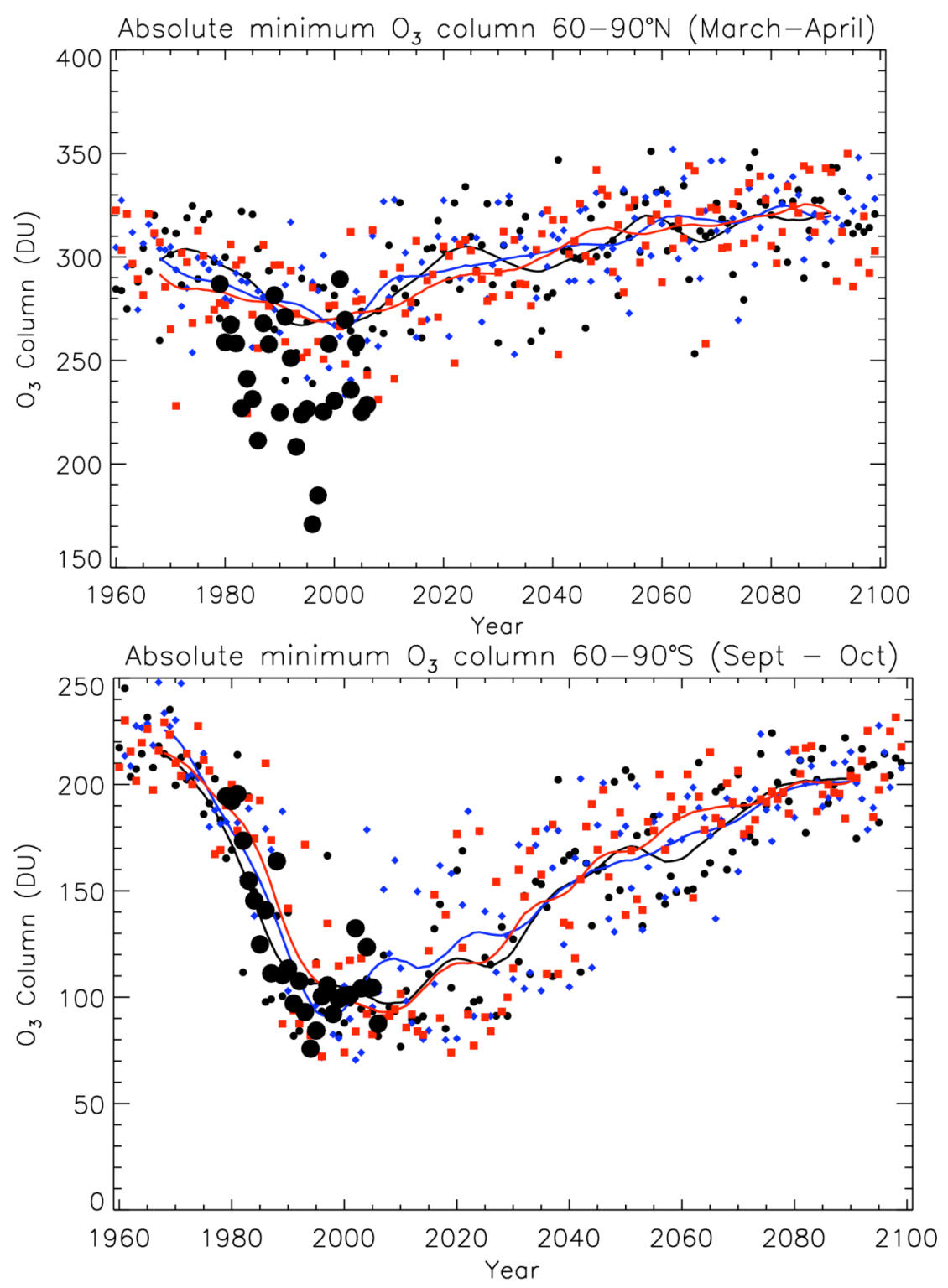

Figure 12. Time series of minimum springtime polar ozone from 1960 to 2100 from CMAM, in the (a) Arctic and (b) Antarctic. The colour symbols show the individual years for each ensemble member, while the colour lines are the same results smoothed with a Gaussian filter with a width of 8 year. Observations from Bodeker et al. (2005) are shown by the black dots. Courtesy of David Plummer, Environment Canada. 